NBER WORKING PAPER SERIES

\title{
CHARACTERISTICS OF OBSERVED LIMIT ORDER DEMAND AND SUPPLY SCHEDULES FOR INDIVIDUAL STOCKS
}

\author{
Jung-Wook Kim \\ Jason Lee \\ Randall Morck \\ Working Paper 14733 \\ http://www.nber.org/papers/w14733 \\ NATIONAL BUREAU OF ECONOMIC RESEARCH \\ 1050 Massachusetts Avenue \\ Cambridge, MA 02138 \\ February 2009
}

We thank Hyeon Kee Bae, Utpal Bhattacharya, Wonseok Choi, David Feldman, Lawrence Glosten, Jarrad Harford, Mark Huson, Aditya Kaul, Alok Kumar, Ki Bong Lee, Kyung-Mook Lim, Raymond Liu, Ernst Maug, Vikas Mehrotra, Jeffrey Pontiff, Barry Scholnick, Hanfeng Shen, Andrei Shleifer, Jeremy Stein, Peter Swan, Bohui Zhang, students in Andrei Shleifer's behavioral finance seminar course at Harvard University, and seminar participants at the University of Alberta, the University of Amsterdam, Arizona State University, the City University of Hong Kong, Erasmus University of Rotterdam, Seoul National University, and the University of New South Wales for helpful comments. We gratefully acknowledge financial support from the University of Alberta SAS fellowship and the Social Sciences and Humanities Research Council. The views expressed herein are those of the author(s) and do not necessarily reflect the views of the National Bureau of Economic Research.

NBER working papers are circulated for discussion and comment purposes. They have not been peerreviewed or been subject to the review by the NBER Board of Directors that accompanies official NBER publications.

(C) 2009 by Jung-Wook Kim, Jason Lee, and Randall Morck. All rights reserved. Short sections of text, not to exceed two paragraphs, may be quoted without explicit permission provided that full credit, including $\odot$ notice, is given to the source. 
Characteristics of Observed Limit Order Demand and Supply Schedules for Individual Stocks Jung-Wook Kim, Jason Lee, and Randall Morck

NBER Working Paper No. 14733

February 2009

JEL No. G01,G10,G14

\begin{abstract}
$\underline{\text { ABSTRACT }}$
Using complete order books from the Korea Stock Exchange for a four-year period including the 1997 Asian financial crisis, we observe (not estimate) limit order demand and supply curves for individual stocks. Both curves have demonstrably finite elasticities. These fall markedly, by about $40 \%$, with the crisis and remain depressed long after other economic and financial variables revert to pre-crisis norms. Superimposed upon this common long-term modulation, individual stocks' supply and demand elasticities correlate negatively at high frequencies. That is, when a stock exhibits an unusually elastic demand curve, it tends simultaneously to exhibit an unusually inelastic supply curve, and vice versa. These findings have potential implications for modeling how information flows into and through stock markets, how limit order providers react or interact to information flows, how new information is capitalized into stock prices, and how financial crises alter these processes. We advance speculative hypotheses, and invite further theoretical and empirical work to explain these findings and their implications.
\end{abstract}

Jung-Wook Kim

Assistant Professor of Finance

School of Business

University of Alberta

Edmonton, Alberta

Canada T6G 2R6

jungwook.kim@ualberta.ca

Jason Lee

Associate Professor of Accounting

University of Alberta

Edmonton AB Canada T6G 2R6

jason.lee@ualberta.ca

\author{
Randall Morck \\ Faculty of Business \\ University of Alberta \\ Edmonton, CANADA T6G 2R6 \\ and NBER \\ randall.morck@ualberta.ca
}




\section{Introduction}

Complete limit order books, with each entry flagged as a buy or sell, for all Korean listed stocks from December 1996 to December 2000 let us observe the whole demand and supply curves of limit orders for each individual listed stock at any instant in time. We do this twice each day - once at the beginning of trading and again at 2:30 PM, half an hour before the market's close. ${ }^{1}$ Since the market opens with a call auction, but then switches to continuous trading, this lets us explore demand and supply under the two microstructure alternatives. Since our sample period includes 1997 and 1998, we can also compare demand and supply curves before, during, and after the Asian financial crisis.

Because we observe entire demand and supply curves for limit orders, we measure the elasticity of each curve separately and directly, rather than jointly and by inference from prices and quantities traded. This sidesteps entirely the standard identification problems associated with elasticity estimation using observed quantities traded and market prices (or prices near the market prices). This also lets us compare the two elasticities and investigate the relationship between them. To the best of our knowledge, this is the first study to investigate these issues.

Our main results are as follows.

First, individual stocks’ limit order supply and demand elasticities are significantly less than infinity, in that their reciprocals differ significantly from zero. This is consistent with theories of information capitalization that derive stock prices from the intersections of finitely elastic demand and supply curves for each stock (e.g., Harrison and Kreps, 1978; Grossman and Stiglitz,1980). A caveat is in order, for our limit order books do not, of course, reveal the total demand and supply that would arise at each hypothetical price. These totals would be limit orders already in the books plus new limit orders and market orders that

\footnotetext{
${ }^{1}$ The KSE was open Saturday mornings until December 5, 1998, so on Saturdays during that period the second elasticity is estimated at 11:30 AM instead of 2:30 PM. Dropping these observations does not qualitatively change any of our results.
} 
would have been submitted were the price to have moved to that hypothetical level. We only observe the first of the three components, so our elasticities of limit order supply and demand may well underestimate the elasticities of the total supply and demand curves for individual stocks. In Korean data, this problem is mitigated because market orders are little used and because limit orders are costless unless executed, so a shareholder willing to sell at a price above the current market price, for example, has nothing to lose except private information by submitting out of the market sell limit orders.

Second, both demand and supply elasticities exhibit a common long run modulation, which change dramatically during the Asian financial crisis. Before the crisis, both average around 36. That is, a one percent price change commands a 36 percent change in quantity demanded or supplied. Both values drop to roughly 22 after the crisis. Unlike many other economic and financial indicators, which fluctuate dramatically around the crisis before reverting to their pre-crisis levels, individual stocks' limit order elasticities remain at these new average levels - apparently permanently. This implies a permanently elevated heterogeneity of investors' valuations after the crisis. The direction of this shift is intriguing, for post-crisis reforms are thought to have enhanced transparency and the advent of online trading is thought to have reduced transactions costs (Kim and Kim, 2008; Kwak, 2007). These findings raise the possibility of elevated information asymmetry and/or risk aversion, constraining information flow through a stock market years after a major financial crisis, with reduced limit order depth around market prices perhaps leaving stock prices more vulnerable to liquidity-driven fluctuations.

Third, superimposed on this common long run modulation, the two elasticities exhibit a negative correlation at high frequencies. That is, stocks that develop unusually elastic demand curves tend simultaneously to develop unusually inelastic supply curves and vice 
versa. This high frequency correlation is more strongly negative in 2:30 PM elasticities than in opening auction elasticities.

This finding raises the possibility of a feedback. For example, demand elasticity might fall as buy-side limit order book depth evaporates in response to aggressive sell-side orders that flatten a stock's supply curve. This sort of feedback reinforces the importance of selecting relatively information-free changes in quantities demanded or sought when estimating individual stocks' demand or supply elasticities (Shleifer, 1986; Wurgler and Zhuravskaya, 2002). Such feedback is also consistent with the conclusions of French and Roll (1986), Roll (1988), and others regarding information propagation in financial markets: most new information is uncovered by private investors and revealed sequentially through their trading.

Because limit orders greatly preponder market orders in Korea (See Section 3.2 below), and because Korean limit order books retain considerable depth well away from market prices, we can measure elasticities across broad price ranges, consistent with economically significant fundamental valuation heterogeneity across limit order providers. This complements previous work using strategic limit order placement near the market price to gauge local elasticities (Kalay et al., 2004).

The remainder of the paper is organized as follows. Section 2 discusses other relevant research. Section 3 discusses the data and elasticity measurement procedure. Section 4 describes our findings, and Section 5 concludes.

\section{Relation to Previous Studies}

The wheelhorses of asset pricing (Markowitz, 1952; Tobin, 1958; Sharpe, 1964; Lintner, 1965) postulate that individual stocks have infinitely many perfect substitutes in other stocks or portfolios, and so have horizontal demand and supply curves. A parallel literature assumes 
individual stocks have finitely elastic demand and supply schedules reflecting heterogeneous valuations across investors (e.g., Grossman and Stiglitz, 1980).

The virtues of the wheelhorses are elegance and simplicity; those of Grossman and Stiglitz (1980) and their descendents are compatibility with increasingly persuasive - though still disputable - empirical evidence of economically significant valuation heterogeneity. This debate turns on abnormal returns associated with private information (French and Roll, 1986; Roll, 1988); secondary offerings (Scholes, 1972; Allen and Postlewaite, 1984; Mikkelson and Partch, 1985; Loderer et al., 1991); repurchases (Bagwell,1992); and index revisions (Shleifer, 1986; Harris and Gruel, 1986; Jain, 1987; Dhillon and Johnson, 1991; Beneish and Whaley, 1996; Lynch and Mendenhall, 1997; Liu, 2000; Kaul et al., 2000; Greenwood, 2005). Also consistent with valuation heterogeneity are finitely elastic demand and supply schedules observed in auctions (Bagwell, 1992; Kandel et al., 1999; Liaw et al., 2000); patterns in nearmarket limit orders (Kalay et al., 2004; Sandås, 2001), inexplicably large normal trading volumes (Varian, 1985, 1989); persistent pricing anomalies (Shleifer, 2000; Shiller, 2002), and historical accounts of investor behavior during alleged stock market manias and panics (Kindleberger, 1978). Shleifer and Vishny (1997) go furthest, arguing that a realistic assessment of arbitrage costs precludes the assumption of homogenous information.

Elaborations of the basic Grossman and Stiglitz (1980) framework posit investors with different information sets (Blough, 1988; Glosten, 1994), different ways of processing information (Hindy, 1989), different abilities to process information (De Long et al., 1990, Barber and Odean, 2000; Grinblatt and Han, 2005), different priors (Kandel and Pearson, 1995), differences of opinion more generally (Varian 1985, 1989; Harris and Raviv, 1993; Kandel and Pearson 1995; Fama and French 2007), and different time preferences (Foucault et al., 2005). Glosten's (1994, p. 1129) observation that "the possibility of information- 
motivated trades ... implies that the schedule of offers is generally upward sloping” pertains to most such approaches.

These approaches are clearly interrelated. For example, heterogeneous impatience might reflect heterogeneous beliefs about the future, heterogeneous abilities to predict the future, or heterogeneous levels of irrational optimism or pessimism. Nonetheless, heterogeneous impatience attracts special interest in the microstructure literature as potentially consistent with information set homogeneity if investors have heterogeneous and exogenously determined levels of impatience. For example, investors confronted with sudden medical or legal bills might knowingly sell shares at depressed prices to obtain cash immediately. Parlour (1998) achieves this by assuming (p. 804) that investors price common future cash flow estimates with discount rates drawn from an exogenously given distribution.

Patient investors can thus gain by placing limit orders above and below a stock's fundamental value, providing immediate execution to impatient investors (Handa and Schwartz, 1996). Such models explain locally elastic demand and supply curves for limit orders near the market price (Sandås, 2001; Kalay et al., 2004), since competition between providers of immediate execution precludes limit orders far away from the market price. Our finding of substantial limit order depth far away from market prices, while not inconsistent with heterogeneous patience, is arguably more consistent with other drivers of heterogeneous valuations, such as heterogeneous information.

Hollifield et al. (2004, 2006) model impatience and information heterogeneity in concert, and conclude that the two are inseparably confounded and must be considered jointly. This is because "traders with high private values submit buy orders with high execution probabilities. Traders with low private values submit sell orders with high execution probabilities. Traders with intermediate private values either submit no orders, or submit buy or sell orders with low execution probabilities” (Hollifield et al., 2006, p. 2760). Intuitively, 
investors with private information provide liquidity at better prices than other potential providers, making actual liquidity provision a by-product of heterogeneous valuations. This prediction is confirmed experimentally (Bloomfield et al., 2005).

Since we directly observe both demand and supply elasticities, we can also test for relationships between them. Valuation heterogeneity driven by patience heterogeneity is consistent with a static limit order book. But if investors have different information or different information processing capabilities, they should monitor each other's trades to infer each other's private valuations (Grossman and Stiglitz, 1980; Shleifer and Vishny, 1997). This implies a dynamic feedback in limit order books, with uninformed limit order providers reacting to likely informed trading by withdrawing limit orders to reduce expected adverse selection costs (Harris, 1998; Parlour, 1998; Sandås, 2001; Goettler et al., 2009).

Our finding of a negative correlation between supply and demand elasticities at high frequencies validates the importance of investigating these dynamics, and suggests directions for future theoretical work in this area. A formal model is beyond the scope of this paper, but the logic can be laid out readily. Assume the information propagation framework proposed by French and Roll (1986) and Roll (1988) is correct: a specific subset of investors are the first to learn of new information, and others only learn of it by watching for unusual trading patterns that signal new private information. As trades execute at changing prices, limit order providers observe the valuations of other investors, and use this information to update their own fundamental value estimates, as well as the uncertainty they attach to those estimates; and hence also their limit orders. This point seems especially important given Roll (1988), who shows that stock price fluctuations usually do not correspond to public information events. From this, he infers that stock price changes are typically caused by investors seeking to gain from private information they acquire. This suggests that traders on one side of the limit order book may often be at an information advantage to those on the other side. For 
example, if a subset of investors learns a stock is underpriced, they should enter large buy orders at or just above the market price, flattening the demand curve. Seeing these executed, uninformed sell-side investors would presumably withdraw limit order depth near the market price, steepening the supply curve. Such a feedback might be represented with an impact function, extending Kyle (1985) or Sandås (2001); or by generalizing the “crowding out” effect in Parlour (1998) or Goettler et al. (2009).

Consistent with the intuition underlying these conjectures, Kavajecz (1999) finds specialists and limit order traders in the U.S. reducing depths around information events, thereby reducing their exposure to adverse selection (Hollifield et al., 2004, 2006). Also consistent with this intuition, Goldstein and Kavajecz (2004) report limit order traders remaining inactive or even withdrawing when the plummeting Dow Jones Industrial Average triggered circuit breakers that halted all trading on October 27, 1997.

\section{Measuring Elasticities}

This section describes how we measure elasticities of limit order demand and supply of individual stocks. It first describes the trading system of the Korea Stock Exchange (KSE) and the raw trade and quote data it generates, then how we construct demand and supply schedules for each stock twice a day, and finally how we summarize the shapes of those curves as elasticities.

\subsection{Market Microstructure}

The KSE is an order driven market, in that it has no designated market makers or specialists. Any investor is free to make a market in any stock, however this entails certain costs. All investors, including brokers, pay a $0.3 \%$ stamp tax on executed sales. Online trading started in 1997 with fees of 0.5\%, matching standard brokerage fees at the time. But online fees fell 
sharply after June 1998 as competition began in earnest. Tick sizes range from $0.1 \%$ to $0.5 \%$ depending on a stock’s price range. For example, a $\$ 5,000$ stock is priced in $¥ 5$ increments, while a $\$ 50,000$ stock is priced in 50 ticks. Bid-ask spreads are thus not entirely endogenous.

The investor base also changes with time. Before May 1998, foreign ownership was capped, limiting foreigners' ability to buy aggressively if the firm already had large foreign blockholdings. After May 1998, all such restrictions disappeared.

Trading begins at 9:00 AM with a call market - an auction in which accumulated bids and offers, taken as simultaneous, are matched to generate one opening price for each stock. In our data, 19.10 percent of buy orders and 21.14 percent of sell orders are submitted to opening sessions.

Subsequent prices, until 10 minutes before the closing time at 3:00 PM, are set in continuous trading. ${ }^{2}$ In the last 10 minutes, another auction market session determines prices. Orders not fully filled in the opening auction pass into continuous trading unless cancelled or revised. An automatic trading system records all outstanding limit orders and automatically crosses new market and limit orders with these, or with opposite market orders. ${ }^{3}$ The computerized order-routing system prioritizes by price and then time.

\subsection{Trade and Quote Records Data}

Our Korean Stock Exchange Trade and Quote (KSETAQ) data are computer records from this system. They include all KSE transactions and limit orders - filled and unfilled. Each record gives a ticker symbol, a date and precise time; a flag for buy versus sell orders; and, for limit orders, the price. We include only transactions involving common shares, so that

\footnotetext{
${ }^{2}$ Before May 22, 2000, the KSE held separate morning (9:00 AM to 12:00 AM) and afternoon (1:00 PM to 3:00 PM) sessions, each commencing with a call market.

${ }^{3}$ For additional detail, see, e.g., Choe et al. (1999).
} 
each firm is represented by only one listed security.

We can further separate data used in the opening auctions from continuous trading data. Margin and short sale orders are also specially flagged. Our sample contains complete data from December $1^{\text {st }} 1996$ to December $31^{\text {st }}$ 2000, and Table 1 summarizes its composition.

\section{[Table 1 about here]}

In constructing demand and supply schedules, we focus on limit orders because market orders, by definition, do not specify prices. ${ }^{4}$ Also, market orders are a very small fraction of total orders on the KSE. Table 1 shows limit orders comprising 94.78 percents of buy orders and 92.99 percent of sell orders. The rarity of market orders likely reflects their novelty. Market orders were introduced by the KSE on November $25^{\text {th }} 1996$, only a few days before our sample period begins, and remained little used. ${ }^{5}$ We hope to explore this event and its implications in future work.

We then take two snapshots per day of each stock’s complete limit order book. The first is at the opening auction, and the second is at 2:30 PM - thirty minutes before trading ends. Unexecuted limit orders expire at the end of the day, so one day's limit orders do not typically reappear the next day.

\subsection{Demand and Supply Schedules}

To gauge elasticities, we first plot out the limit order demand and supply schedules of each individual stock - first in the opening auction and then at 2:30 PM amid continuous trading.

\footnotetext{
${ }^{4}$ Bloomfield et al. (2005) and Kaniel and Liu (2006) argue that informed investors should prefer limit orders to market orders. Thus, limit orders are likely more useful for gauging information heterogeneity among investors.

${ }^{5}$ One financial analyst we asked about this proposed a starkly behavioral motive, resonant of the "default option" bias explained in Thaler and Sunstein (2008): the standard electronic form for entering orders has a blank for price, so most investors enter one.
} 
This is done precisely as in economics principles textbooks, and is best illustrated with an example.

[Figure 1 about here]

Figure 1 graphs the demand and supply schedules on November $11^{\text {th }} 2000$ of Samsung Electronics, a large and heavily traded KSE listing. ${ }^{6}$ These graphs are constructed by horizontally summing all limit orders that would execute at each theoretical price. The sum of all buy orders that would execute at a given price $p$ is the demand for Samsung Electronics at that price. As the price is decreased, tick by tick, successively more buy limit orders join the executable list so the demand curve reaches further to the right at lower prices. The sum of all sell orders that would execute at price $p$ is analogously the supply of Samsung Electronics shares offered at that price. Again, as the price rises in one tick increment, additional sell orders join that sum and the supply curve extends increasingly far to the right at successively higher prices.

[Figure 2 about here]

The demand and supply schedules at both the opening auction and 2:30 PM resemble those in standard economics textbooks, with the obvious proviso that the area to the left of the market price is unobservable in continuous trading. Figure 2 shows Samsung Electronics' demand and supply schedules at 15-minute intervals throughout the day including the opening and closing auctions. The 2:30 PM snapshots are typical. Graphs on other dates and for other stocks look similar to those shown in the figures.

\footnotetext{
${ }^{6}$ We randomly choose 3 other stocks from large, medium and small capitalization groups. These graphs all resemble Figure 1.
} 
Using this technique, we construct supply and demand curves for each listed stock twice each day, precisely as in Figure 1. We begin by constructing analogs of Figure 1 for each stock $j$. For each bid price $p$, we sum the bid orders that would execute to obtain demand $^{7}$

$$
d_{j}(p)=\sum_{b=1}^{B} n_{b j} \delta\left(p_{b j} \geq p\right)
$$

with $b$ an index of bid limit orders, $n_{b j}$ the number of shares sought in order $b$, and $\delta\left(p_{b j} \geq p\right)$ an indicator set to one if order $b$ executes at price $p$ and to zero otherwise. The supply of stock $j$ at $p$ is analogously defined over ask limit orders, indexed by $a$, as follows.

$$
s_{j}(p)=\sum_{a=1}^{A} n_{a j} \delta\left(p_{a j} \leq p\right)
$$

For each stock, at any point in time, we thus map price $p$ into a total quantity of stock $j$ demanded, $d_{j}(p)$, and a total quantity supplied, $s_{j}(p)$. This technique reveals demand and supply schedules for each stock at each day's opening auction and again at 2:30 PM. Note that these demand and supply schedules are observed, not estimated. Simultaneous equations identification problems do not arise.

\subsection{Alternative Approaches to Measuring Elasticities}

Kalay et al. (2004) measure demand and supply elasticities for stocks traded on the Tel Aviv Stock Exchange from limit orders adjacent to market prices. They report unambiguously

\footnotetext{
${ }^{7}$ When an order is submitted but subsequently cancelled, we exclude it in constructing the demand and supply schedules. Similarly, for any revised order, we use the revised price and/or quantity.
} 
finite elasticities, but caution that their estimates depend critically on their assumptions about the shareholder base.

Specifically, they measure elasticities as percentage changes in quantities divided by percentage changes in prices and take the former to be the quantity offered or sought divided by the 'total quantity of shares'. If this denominator is shares outstanding, all shares are assumed to be for sale and their elasticities are very small: 0.083 and 0.009 for mean local demand and supply elasticities, respectively. If they scale instead by opening volume, only shareholders active at that time are assumed to be willing to trade and their elasticities are large: 415.4 and 63.6 for demand and supply elasticities, respectively. Scaling by total shares in the order book at open, or by mean daily volume, yields only slightly less extreme point estimates. All of these scaling methods are defensible, as are others - such as the public float, or a smoothed trading volume.

This issue affects the estimation of any demand and supply elasticities in any markets - for example, the potential total quantity of oil might be current inventories, "proven" reserves, "possible” reserves, or all geological deposits. While accepting the validity of this issue, we follow the conventional econometrics textbook approach (e.g., Greene, 1993) and estimate elasticities as log differences in quantities offered, or sought, divided by log differences in prices. This lets the data choose a denominator at the cost of imposing a constant elasticity assumption across the whole length of each side of the limit order book. This assumption is clearly restrictive, but parsimoniously characterizes valuation heterogeneity across the broad price ranges we observe in the data.

Since measuring this heterogeneity is our primary interest, the log on log specification is defensible. However, alternative assumptions may well be preferable in other contexts. Subsequent sections therefore examine the robustness of our results to modifying this assumption and estimating elasticities using subsets of limit order books. 


\subsection{Elasticity Measurement Procedure}

To measure the elasticity of demand in limit orders for firm $j$ 's stock at time $t$, we regress the logarithm of total demand at that time at price $p_{k}, \ln d_{j, t}\left(p_{k}\right)$, on the logarithm of $p_{k}$,

$$
\ln d_{j, t}\left(p_{k}\right)=a_{j, t}-\eta_{j, t}^{D} \ln p_{k}+u_{j, t, k}
$$

The elasticity of demand at time $t, \eta_{j, t}^{D}$, the percentage decrease in the quantity of stock $j$ sought given a one percent price rise, is thus minus one times the coefficient of $\ln p_{k}$ in [3].

The elasticity of supply at time $t, \eta_{j, t}^{S}$, is the percentage increase in the quantity of stock offered given a one percent price rise, and so is measured by the coefficient on $\ln p_{k}$ in [4].

[4] $\quad \ln s_{j, t}\left(p_{k}\right)=b_{j, t}+\eta_{j, t}^{S} \ln p_{k}+v_{j, t, k}$

Both demand and supply elasticities are each measured only when we have over five price-quantity pairs. In the final sample, the mean (median) number of pairs used is 17 (13) for opening auction demand elasticities and 17 (12) for opening auction supply elasticities, and 17 (14) and 21 (16) for 2:30 PM demand and supply elasticities, respectively. The mean (median) regression $R^{2}$ of [3] at the opening auction and at 2:30 PM are 74\% (76\%) and 64\% (65\%) respectively; and, those of [4] are 80\% (82\%) and 72\% (74\%) respectively, suggesting that the log on log specification parsimoniously summarizes the data.

Finally, although [3] and [4] use regression coefficients as elasticity measurements, no simultaneity bias arises. This is because we are not jointly estimating demand and supply 
curves from the same data. Rather, we are plotting out observed demand and supply curves precisely and then using [3] and [4] to measure the slope of each side of the limit order book.

\subsection{Limit Order Book Range}

As noted in Section 2, the elasticities of demand and supply schedules could reflect various sorts of investor heterogeneity - including information heterogeneity, patience heterogeneity, or some combination of the two. If investors are heterogeneously patient, finitely elastic demand and supply schedules could persist despite investors having homogenous information. This is because impatient investors compensate patient investors for immediate order execution by acquiescing to slightly disadvantageous prices.

As noted above, the KSE lacks designated market makers. Instead, new orders are matched against outstanding orders. But private traders can act as de facto market makers by standing ready to buy or sell at prices slightly below or above the market price. Handa and Schwartz (1996) and Foucault et al. (2005) model such private market makers’ profits from trading at advantageous prices offsetting trading costs, non-execution costs, and disadvantageous fundamentals news; and suggest that limit orders around market prices may be associated with virtual market making rather than with genuine heterogeneous valuation.

Hollifield et al. (2004, 2006) argue that investors whose private information implies valuations different from the market price are also those who provide liquidity as de facto market makers. If investors have more homogenous information, and are more certain of their valuations, this model implies that such de facto market makers would maximize their quasirents by placing limit orders close to the market price, where execution is likely. In contrast, if investors have more heterogeneous information or attach less certainty to their valuations, de facto market makers would place limit orders farther away from the current market price to avoid adverse selection. 
We therefore examine the distribution of prices in limit order books. We believe Ockham's razor favors these limit order books reflecting genuinely heterogeneous fundamental value estimates for several reasons:

First, the price ranges at which we observe substantial limit order depth are quite broad, and so seem a priori inimical to de facto market making as a sole, or even primary explanation. Panels A and B of Table 2 show substantial limit order depths beyond 3\% away from the observed market price - open prices in morning auctions or bid-ask midpoints at 2:30 PM for each schedule. This is equivalent to a $6 \%$ spread in a specialist market. These limit orders represent about $71 \%$ and $74.1 \%$ of total limit buy and sell orders for the opening auction and $69.4 \%$ and $75.2 \%$ for $2: 30$ PM, respectively. Only $10.5 \%$ (9.1\%) of total quantities demanded (supplied) fall within a one percent range around the market price at the opening auction and only $10.2 \%(6.6 \%)$ at $2: 30$ PM. Such a substantial width in the limit order distribution seems consistent with heterogeneous investor beliefs, or at least, liquidity provision by investors with heterogeneous valuations as in Hollifield et al. (2004, 2006).

[Table 2 about here]

Second, Korea levies a $0.3 \%$ Tobin tax on all stock sales, even by brokers' trading on their own accounts. Public shareholders serving as liquidity providers confront even higher transactions costs, for in 2000 , brokerage fees ranged from $0.35 \%$ to $0.5 \%$, though online trading costs fell sharply after June 1998, and now range between $0.025 \%$ and $0.1 \%$. Such costs could render limit orders solely to provide liquidity more costly.

Third, Table 1 shows market orders comprising only 5.22\% of shares sought and 7.01\% of shares offered. If limit orders existed primarily to provide liquidity around market prices, they ought not to preponder market orders greatly, for the latter ought to include much 
of the demand for quick execution. Aggregated limit order magnitudes, roughly sixteen to twenty-fold greater than market orders at 2:30 PM and seven to thirteen-fold greater in the opening auction, seem superfluous.

This evidence is admittedly circumstantial, for our findings could conceivably just reflect substantial impatience heterogeneity, rather than information-based heterogeneity. We therefore pursue this issue further below. First, Section 3.7 re-estimates elasticities excluding price-quantity pairs proximate to market prices, where liquidity provision absent valuation heterogeneity is most plausible. Second, Sections 4.3, 4.4, and 4.5 demonstrate a high frequency negative correlation between elasticities of demand and supply. Based on these findings, Section 4.6 argues that information heterogeneity among investors is a plausible explanation of our findings.

\subsection{Whole and Cored Elasticities}

Equations [3] and [4] assume constant elasticity across all prices. This assumption injects noise if the true elasticity varies across prices, but becomes even more problematic if Hollifield et al. (2004, 2006) do not apply; and limit orders near the market price reflect competitive market making by liquidity providers with no genuinely divergent valuations. We can mitigate, and evaluate, these concerns by estimating elasticities after removing observations near the market price, where competitive market makings unassociated with valuation heterogeneity is most likely.

We define near-market limit orders as those priced in the interval $\left(p_{m}(1-k), p_{m}(1+\right.$ $k$ )), centered around the market price, $p_{m}$, with $k$ set to one, two, and then three percent of the market price. By dropping price-quantity pairs with prices in these successively larger nearmarket intervals, we obtain cored supply and demand schedules, so-named because of the holes around their market prices. At all non-near-market prices, these demand and supply 
schedules are identical to those described above. That is, given a supply schedule of pricequantity pairs $\left\{(p, s(p)\}\right.$, we denote the corresponding cored supply schedules, $C_{s}(k)$, for $k=$ one, two, or three percent, as

$$
C_{s}(k) \equiv\left\{(p, s(p)) \mid p \in\left(0, p_{m}(1-\mathrm{k})\right] \cup\left[p_{m}(1+\mathrm{k}),+\infty\right)\right\}
$$

Cored demand schedule are similarly defined.

We then run [3] and [4] on these cored demand and supply schedules to obtain cored elasticities of demand or supply.

\section{Empirical Results}

This section first reports summary statistics of demand and supply elasticities; and then presents firm-level daily panel regressions. We divide our sample period into three subperiods; a pre-crisis period of December 1996 through October 1997, an in-crisis period of November 1997 to October 1998, and a post-crisis period of November 1998 to December 2000. This division of the sample period into three sub-periods follows the definition in Kim and Wei (2002). ${ }^{8}$

[Figure 3 about here]

\subsection{Magnitudes}

Panels A and B of Figure 3 plot the time series of daily mean elasticities against time; Panel C of Figure 3 plots the KSE index for the same period. Table 3 reports the summary statistics of underlying firm-level daily elasticities of demand and supply curves. Table 3 shows the

\footnotetext{
${ }^{8}$ In November, 1997, the Bank of Korea stopped defending Korean Won and Korean government requested IMF bail-out.
} 
median demand elasticities to be about 20 both in opening auctions and at 2:30 PM; while the median supply elasticities are 24 in opening auctions and 23 at 2:30 PM. A one percent increase in price thus induces roughly a 20 percent drop in demand and a 23 percent rise in supply. ${ }^{9}$

[Table 3 about here]

All of the elasticity estimates in Panels A and B of Table 3 are significantly below infinity; in the sense that their reciprocals significantly differ from zero. Whether we use whole demand and supply schedules or cored demand and supply schedules to estimate $\eta^{D}$ and $\eta^{S}$, standard t-tests and rank tests show the means and medians of both $1 / \eta^{D}$ and $1 / \eta^{S}$ to differ significantly from zero $(\mathrm{p}<0.0001)$.

Our elasticity measurements generally exceed the 10.50 figure imputed by Kaul et al. (2000), the 7.89 estimate obtained by Wurgler and Zhuravskaya (2002), the mean (median) elasticity of 0.68 (1.05) reported by Bagwell (1992) from Dutch auction share repurchases, and the mean (median) estimates of 2.91 (2.47) by Kandel et al. (1999) from IPO data. Our estimates lie between the lower and upper bounds determined by Kalay et al. (2004).

These differences might reflect different methodologies, unique information events used in some of the studies, or different institutional arrangements in different countries or time periods. For example, KSE investors observe quantities demanded and supplied at the five best prices during our sample period, whereas investors in other stock markets have less information, so higher average KSE elasticities are not entirely surprising.

We also check the differences between elasticities observed in opening auctions and those observed at 2:30 PM. If uncertainty regarding private information were appreciably

\footnotetext{
${ }^{9}$ Cored elasticities generate similar patterns. Section 4.2 discusses this issue in detail.
} 
resolved by trading, as proposed by Glosten and Milgrom (1985), elasticities should rise through the day. Through our sample period, 2:30 PM mean elasticities generally exceed mean opening auction elasticities - consistent with the findings of Kalay et al. (2004). However, our analogous median measurements show no discernable intraday pattern.

\subsection{Harmony at Low Frequencies}

One advantage of a long time series that includes a crisis is that it allows a comparison of the magnitudes of elasticities before and after the crisis using one measurement methodology. Thus, even if absolute magnitudes are not directly comparable across studies that use different estimation methods, we can make valid comparisons over time for KSE stocks. The average elasticities of both demand and supply fluctuate far more during the last months of 1997 and the first months of 1998 than either before or after. This period of instability corresponding to the onset of the 1997 Asian financial crisis, evident in the KSE index in Panel A of Figure 3, is unsurprising.

More intriguingly, elasticities of both demand and supply are markedly lower after this interlude of instability, implying more heterogeneous valuations across investors in the post-crisis period. Table 3 shows a 39\% drop, from 30.0 to 18.3, in the median opening auction demand elasticity; and a 41\% drop, from 36.9 to 21.9 in the median opening auction supply elasticity. Similarly dramatic reductions are evident in 2:30 PM measurements; and in the means as well. These differences are all statistically significant $(p<0.0001)$. Note that even after the KSE market index reverts to the pre-crisis level, elasticities of both curves remain depressed through the remainder of our sample period. This suggests that the crisis permanently altered both demand and supply curves, to reflect permanently elevated heterogeneity across investors in firm valuations.

Substantial fluctuation at higher frequencies is clearly superimposed on this step 
function. However, elasticities fluctuate around stable averages in both the pre- and postcrisis periods, and no trend in the magnitude of these higher frequency fluctuations is immediately evident for each sub-period. These regularities suggest an underlying factor, common to demand and supply elasticities, which follows a step function; but otherwise changes little before or after the crisis. Possible candidates would be several institutional reforms that have permanent impact. However, we can exclude them because many of postcrisis reforms arguably rendered the country's equity market more transparent and thus lowered arbitrage costs. Greater transparency should decrease information heterogeneity, leaving both curves more elastic, all else equal. The advent of low-cost online trading after June 1998, at first blush at least, should have reduced arbitrage costs and flattened demand and supply curves as well.

In our sample, supply is generally more elastic than demand. The difference in means is highly significant $(p<0.0001)$ throughout all three sub-periods. Thus higher supply elasticities are not artifacts of fire sales during the crisis period. Kalay et al. (2004) find supply less locally elastic (around market prices) than demand for stocks traded in Tel Aviv Stock Exchange (TASE), and posit short sale constraints as an explanation. Short sales are uncommon on the KSE, comprising only about $0.5 \%$ of pre-crisis sell orders and an essentially negligible fraction in the post-crisis sub-period. Thus, our relatively high supply elasticities are not readily explained by more intense short sale activities in KSE than in TASE.

[Figure 4 about here]

To see if our results are driven by orders near market prices, we repeat the exercise using cored elasticities. Figure 4 shows the permanent decrease in mean elasticities is robust 
to dropping limit orders priced within one, two, and three percent of the market price. Similar patterns are evident if we use median elasticities instead. Thus, the significant drop in elasticities we observe is not driven by orders near market prices.

Within each sub-period, mean elasticities are larger if the elasticities are estimated using orders farther away from the market price, though this difference attenuates in the postcrisis period. ${ }^{10}$ Higher elasticities for limit orders farther away from the market price in the pre-crisis period are consistent with investors' valuations being more homogeneous before the crisis than after it.

The finite elasticities evident in Panels A and B of Figure 4 throughout our sample period, even after excluding orders near market prices, are consistent with the persistence of economically important information heterogeneity, and thus reinforce the clues in Table 2. Since the KSE lets any trader help make the market in any stock, competitive pressure on de facto market makers lacking any private information would induce large limit orders near the market price where execution probability is large. Although extreme demand for liquidity might occasionally invite such orders farther from the market price, a persistent high density in the tails of the limit order distribution presents at least a strong circumstantial case for information heterogeneity. That is, investors would enter such orders only if they genuinely expected the price to move to a new range. For example, investors holding a stock they believe undervalued might enter high sell orders in anticipation of an upward correction. Investors expecting an overvalued stock to fall might enter low buy limit orders for analogous reasons.

[Figure 5 about here]

\footnotetext{
${ }^{10}$ The slightly higher elasticities generated by dropping limit orders within three percent of the market price may reflect a reduced sample, since we require more than five price-quantity pairs to estimate elasticities. Stocks with scant limit order depth away from the market price thus fall out of the sample, and these may be either thinly traded or subject to little valuation heterogeneity. However, the same pattern is evident using recalculated mean and median elasticities based on the whole demand or supply schedules and on the various cored schedules defined in [5], but using only those firm-day observations for which three percent cored schedules are measurable.
} 


\subsection{Counterpoint at Higher Frequencies?}

Figure 5 plots individual stocks' daily mean demand elasticities against daily mean supply elasticities using first opening auction and then 2:30 PM snapshots, and using first elasticities measured across the whole limit order book and then our various cored elasticities. A clear negative relationship is evident in the 2:30 PM elasticities. A similar negative relationship becomes apparent in the opening auction elasticities after dropping limit orders within one percent of the market price, and persists with the other cored elasticities as well.

[Figure 6 about here]

To verify these visual patterns, we estimate the simple correlation of daily mean demand elasticities with daily mean supply elasticities each month. Figure 6 plots these against time, showing that they jibe roughly with the patterns apparent in Figure 5. The correlation is strongly negative for elasticities based on the 2:30 PM snapshots, regardless of whether we use whole elasticities or cored elasticities. A similarly robust negative correlation of a similar magnitude is evident using cored elasticities, but less apparent in using whole elasticities at the opening auctions.

The crystallization of a clear negative correlation, after dropping limit orders within one percent of the market price at the opening auction, may be explained by Figure 1 . This shows the demand and supply curves at the opening auction intersecting to the right of the price axis. The opening auction includes above-market buy orders and below-market sell orders because investors cannot observe the market price until the auction is completed. In contrast, investors observe the market price at 2:30 PM, precluding above-market buy limit orders and below-market sell limit orders. The orders entered at such disadvantageous prices 
in the opening auction actually execute at the market price, and so are, in effect, transformed into market orders. Consequently, deleting them by using the cored elasticities is clearly warranted.

\subsection{Panel Regressions}

To investigate this contemporaneous negative high frequency correlation further, we turn to panel regressions using daily firm-level elasticities. We demean these data using crosssection means to remove any temporal fixed effects, and also include firm fixed effects to control for any firm characteristics that might affect elasticities. Thus, we run

[6] $\quad \tilde{\eta}_{j, t}^{S}=\alpha_{j}+\beta \tilde{\eta}_{j, t}^{D}+\varepsilon_{j, t}$,

where stock $j$ 's market-adjusted elasticities of supply and demand at time $t$ are $\tilde{\eta}_{j, t}^{S} \equiv \eta_{j, t}^{S}-\bar{\eta}_{t}^{S}$ and $\tilde{\eta}_{j, t}^{D} \equiv \eta_{j, t}^{D}-\bar{\eta}_{t}^{D}$, respectively, with $\bar{\eta}_{t}^{S}$ and $\bar{\eta}_{t}^{D}$ the mean elasticities of supply and demand, respectively, across all stocks at time $t$; and the $\alpha_{j}$ are firm fixed effects. We also cluster standard errors by firm to adjust for any autocorrelation in the elasticities.

[Table 4 about here]

Table 4 presents estimates of $\beta$ from [6] using whole elasticities and the cored elasticities described in [5] for our entire sample period and for the pre-crisis, in-crisis, and post-crisis subperiods. Highly significant negative coefficients arise in every case for the 2:30 PM elasticities, and in every case for the opening auction elasticities of cored demand and supply schedules. The sole exception is opening auction elasticities of whole demand and 
supply schedule. We conclude that the firm-level panel regressions in Table 4 confirm the patterns apparent in Figures 5 and 6.

\subsection{Robustness Checks}

A variety of robustness checks generate qualitatively similar results, by which we mean similar patterns of signs and statistical significance to those in Table 4.

We cluster standard errors by firm. Clustering by time generates qualitatively similar results.

We measure fewer stocks' elasticities when we use cored elasticities, for which we exclude the section of the demand or supply schedule near the market price. This is because we require more than five price-quantity points to take a measurement. The smallest sample arises for elasticities defined using $\mathrm{C}(0.03)$ which encompasses only demand or supply schedule points more than three percent above or below the market price. Rerunning regressions using this smaller set of stocks but using elasticities based on the whole schedules and the other cored schedules, occluding limit orders within only one and two percent of the market, also yields qualitatively similar results. That is, except for opening auction elasticities based on whole schedules, all the coefficients are highly significantly negative.

We rerun the regressions in Panels A and B of Table 4 weighting each pair of elasticities by the firm's market capitalization at the previous day's close. This is to see if our results differ across larger or smaller firms, which might inhabit different information environments for many reasons. Again, qualitatively similar results to those in Table 4 ensue.

\subsection{Clinching the Case for Information Heterogeneity}

A negative contemporaneous correlation between the elasticities of a stock's supply and demand schedules is difficult to explain if finite elasticities reflect only liquidity provision, 
and not information heterogeneity. Absent heterogeneous private valuations, buy-side liquidity provision should not evaporate if sell-side liquidity provision deepens, and vice versa.

However, this high frequency negative correlation between supply and demand elasticities is entirely consistent with some traders acquiring private information, as in French and Roll (1986) and Roll (1988), and with other investors inferring that information by observing trading patterns, as in Glosten and Milgrom (1985). We speculate that aggressive limit order placement by privately informed traders would increase the elasticity on their side of the limit order book; and that investors on the other side, observing this and fearing they are at an informational disadvantage, would withdraw limit order depth, lowering the elasticity on their side of the limit order book. For example, an eruption of large buy orders would flatten the demand curve, but signal sell side limit order providers that private information is afoot. Fearing adverse selection, sell side limit order providers would reduce their exposure by withdrawing limit order depth, rendering the supply curve more inelastic.

This sort of feedback raises interesting possibilities for extending models of information heterogeneity and liquidity provision, such as Hollifield et al. (2004, 2006), to include the reactions of uninformed traders and the process by which private information propagates through the market and becomes public.

\section{Conclusions}

The asset pricing literature descended from Harrison and Kreps (1978) and Grossman and Stiglitz (1980) posits finitely elastic demand and supply curves for individual stocks with elasticities determined by investors' risk aversion, information heterogeneity, and uncertainty regarding fundamental valuations. Blough (1988), Hindy (1989), De Long et al. (1990), Kandel and Peason (1995), Harris and Raviv (1993), Varian (1985, 1989), Shleifer and 
Vishny (1997), and others all elaborate theories along these lines, which in one way or another, all preserve the assumption of finite elasticities.

We observe (not estimate) elasticities of the demand and supply curves of individual stocks' limit orders on the Korea Stock Exchange and find that these are unambiguously finite. Our results, subject to the caveat that limit order books do not measure all latent supply and demand away from the market price, are thus consistent with the approach to asset pricing set forth in this literature.

The Asian financial crisis, which occurred midway through our sample period, upset conventional frameworks for understanding the Korean economy, and induced dramatic changes in the business strategies of many Korean firms. Such factors may have increased the heterogeneity of investors' beliefs about fundamental values. The crisis also reduced the wealth of many investors, and arguably also heightened their perceptions of the risks inherent in equity - factors most readily interpreted as elevated risk aversion among investors. Information heterogeneity and investor risk aversion are both plausible determinants of the elasticities of demand and supply curves for individual stocks in models permitting heterogeneous investor perceptions of fundamental values.

Elasticities of both supply and demand are about $40 \%$ lower in the post-crisis period than in the pre-crisis period, and do not revert within our entire sample period- although other financial and economic indicators do return to their pre-crisis levels. This pattern seems consistent with elevated valuation heterogeneity and uncertainty, with elevated risk aversion, or with both. This pattern is also consistent with investors possessing private information being less likely to enter large orders based on that information, and with liquidity providers fearing trading against better informed investors and therefore being more cautious about providing limit order depth. If so, a financial crisis may render a stock market less able to assimilate private information. 
The elasticities of demand and supply in a stock’s limit order book typically exhibit a contemporaneous negative correlation in high frequency (daily) data. We speculate as to how informed investors entering one side of the market with large orders would flatten one of the two curves, and how uninformed investors on the other side, reacting to this, would withdraw limit order depth, steepening the other curve.

The patterns we detect in the observed (not estimated) limit order elasticities of demand and supply of individual common stocks call for further theoretical work to ascertain the interactions between changing information heterogeneity, valuation uncertainty, and risk aversion. We especially encourage new models of the strategic interactions of risk-averse buyers and sellers of financial assets in markets with heterogeneous information; and of how rational traders infer new private information and react upon detecting it. Of course, we also welcome further empirical work to qualify our findings, geographically or temporally, or to advance alternative explanations of the robust empirical regularities described above.

\section{References}

Allen, Franklin, and Andrew Postlewaite, 1984, Rational expectations and the measurement of a stock's elasticity of demand, Journal of Finance 39, 1119-26.

Bagwell, Laurie S., 1992, Dutch auction repurchases: An analysis of shareholder heterogeneity, Journal of Finance 47, 71-105.

Barber, Brad M., and Terrance Odean, 2000, Trading is hazardous to your wealth: The common stock investment performance of individual investors, Journal of Finance 55, 773-806.

Beneish, Messod, and Robert Whaley, 1996, An anatomy of the "S\&P Game": The effects of changing the rules, Journal of Finance 51, 1909-1930.

Bloomfield, Robert J., Maureen O'Hara, and Gideon Saar, 2005, The “make or take” decision in an electronic market: Evidence on the evolution of liquidity, Journal of Financial Economics 75, 165-200.

Blough, S., 1988, Differences of opinion and the information value of prices, working paper, The Johns Hopkins University.

Choe, Hyuk, Bong-Chan Kho, and René Stulz, 1999, Do foreign investors destabilize stock markets? The Korean experience in 1997, Journal of Financial Economics 54, 227-254.

De Long, J. Bradford, Andrei Shleifer, Lawrence H. Summers, and Robert J. Waldman, 1990, Noise trader risk in financial markets, Journal of Political Economy 98, 703-738.

Dhillon, Upinder, and Herb Johnson, 1991, Changes in the Standard and Poor's 500 list, Journal of Business 64, 75-85.

Fama, Eugene, and Kenneth French, 2007, Disagreement, tastes, and asset pricing, Journal of Financial Economics 83, 667-689. 
Foucault, Thierry, Ohad Kadan, and Eugene Kandel, 2005, Limit order book as a market for liquidity, Review of Financial Studies 18, 1171-1217.

French, Kenneth, and Richard Roll, 1986, Stock return variances: The arrival of information and the reaction of traders, Journal of Financial Economics 17, 5-26.

Goettler, Ronald, Christine Parlour, and Uday Rajan, 2009, Equilibrium in a dynamic limit order market, Journal of Finance, forthcoming.

Glosten, Lawrence, 1994, Is the electronic open limit order book inevitable?, Journal of Finance 49, 1127-1161.

Glosten, Lawrence, and Paul Milgrom, 1985, Bid, ask, and transaction prices in a specialist market with heterogeneously informed traders, Journal of Financial Economics 13, 71-100.

Goldstein, Michael A., and Kenneth A. Kavajecz, 2004, Trading strategies during circuit breakers and extreme market movements, Journal of Financial Markets 7, 301-333.

Greene, William H., 1993, Econometric Analysis, Macmillan Publishing Company.

Greenwood, Robin, 2005, Short- and long-term demand curves for stocks: Theory and evidence on the dynamics of arbitrage, Journal of Financial Economics 75, 607-649.

Grinblatt, Mark, and Bing Han, 2005, Prospect theory, mental accounting, and momentum, Journal of Financial Economics 78, 311-339.

Grossman, Sanford, and Joseph Stiglitz, 1980, On the impossibility of informationally efficient markets, American Economic Review 70, 393-411.

Handa, Puneet, and Robert A. Schwartz, 1996, Limit order trading, Journal of Finance 51, 18351861.

Harris, Lawrence, 1998, Optimal dynamic order submission strategies in some stylized trading problems, Financial Markets, Institutions \& Instruments 7, 1-76.

Harris, Lawrance, and Eitan Gurel, 1986, Price and volume effects associated with changes in the S\&P 500: New evidence for the existence of price pressures, Journal of Finance 41, 815-829.

Harris, Milton, and Artur Raviv, 1993, Differences of opinion make a horse race, Review of Financial Studies 6, 473-506.

Harrison, J. Michael, and David M. Kreps, 1978, Speculative investor behavior in a stock market with heterogeneous expectations, Quarterly Journal of Economics 93, 323-336.

Hindy, A., 1989, An equilibrium model of futures markets dynamics, working paper, MIT.

Hollifield, Burton, Robert A. Miller, and Patrik Sandås, 2004, Empirical analysis of limit order markets, Review of Economic Studies 71, 1027-1063.

Hollifield, Burton, Robert A. Miller, Patrik Sandås, and Joshua Slive, 2006, Estimating the gains from trade in limit-order markets, Journal of Finance 61, 2753-2804.

Jain, Prem, 1987, The effect of stock price of inclusion in or exclusion from the S\&P 500, Financial Analysts Journal 43, 58-65.

Kalay, Avner, Orly Sade, and Avi Wohl, 2004, Measuring stock illiquidity: An investigation of the demand and supply schedules at the TASE, Journal of Financial Economics 74, 461-486.

Kaniel, Ron, and Hong Liu, 2006, So what orders do informed traders use?, Journal of Business 79, 1867-1913.

Kandel, Eugene, and Neil D. Pearson, 1995, Differential interpretation of public signals and trade in speculative markets, Journal of Political Economy 103, 831-872.

Kandel, Shmuel, Oded Sarig, and Avi Wohl, 1999, The demand for stocks: An analysis of IPO auctions, Review of Financial Studies 12, 227-247.

Kaul, Aditya, Vikas Mehrotra, and Randall Morck, 2000, Demand curves for stocks do slope down: New evidence from an index weights adjustment, Journal of Finance 55, 893-912.

Kavajecz, Kenneth A., 1999, A specialist's quoted depth and the limit order book, Journal of Finance 54, 747-771.

Kim, E. Han, and Woochan Kim, 2008, Changes in Korean Corporate Governance: A Response to Crisis, Journal of Applied Corporate Finance 20, 47-58.

Kim, Woochan, and Shang-Jin Wei, 2002, Foreign portfolio investors before and during a crisis, Journal of International Economics 56, 77-96.

Kindleberger, 1978, Manias, Panics, and Crashes: A History of Financial Crises, Basic Books.

Kwak, Hae-Sun, 2007, Three Hundred Frequently Asked Questions on Stock Investment: Theory and Practical Strategy (in Korean), Dong A Il Bo Sa. 
Kyle, Albert, 1985, Continuous auctions and insider trading, Econometrica 53, 1315-1335.

Liaw, Gwohorng, Yu-Jane Liu, and K.C. John Wei, 2000, On the demand elasticity of initial public offerings: An analysis of discriminatory auctions, working paper, Hong Kong University of Science and Technology.

Lintner, John, 1965, The valuation of risk assets and the selection of risky investments in stock portfolios and capital budgets, Review of Economics and Statistics 47, 13-37.

Liu, Shinhua, 2000, Changes in the Nikkei 500: New evidence for downward sloping demand curves for stocks, International Review of Finance 1, 245-267.

Loderer, Claudio, John Cooney, and Leonard van Drunen, 1991, The price elasticity of demand for common stock, Journal of Finance 46, 621-52.

Lynch, Anthony, and Richard Mendenhall, 1997, New evidence on stock price effects associated with changes in the S\&P 500 Index, Journal of Business 70, 351-383.

Markowitz, Harry, 1952, Portfolio selection, Journal of Finance 7, 77-91.

Mikkelson, Wayne H., and M. Megan Partch, 1985, Stock price effects and costs of secondary distributions, Journal of Financial Economics 14, 165-194.

Parlour, Christine, 1998, Price dynamics in limit order markets, Review of Financial Studies 11, 789.

Roll, Richard, 1988, R², Journal of Finance 43, 541-566.

Sandås, Patrik, 2001, Adverse selection and competitive market making: Empirical evidence from a limit order market, Review of Financial Studies 14, 705-734.

Scholes, Myron, 1972, The market for securities: Substitution versus price pressure and the effects of information on share price, Journal of Business 45, 179-211.

Sharpe, William, 1964, Capital asset prices: A theory of market equilibrium under conditions of risk. Journal of Finance 19, 425-442.

Shiller, Robert J., 2002, From efficient market theory to behavioral finance, Journal of Economic Perspectives 17, 83-104.

Shleifer, Andrei, 1986, Do demand curves for stock slope down? Journal of Finance 41, 579-590.

Shleifer, Andrei, 2000, Inefficient markets: An introduction to behavioral finance, Oxford University Press Inc., New York.

Shleifer, Andrei, and Robert W. Vishny, 1997, The limits of arbitrage, Journal of Finance 52, 35-55.

Thaler, Richard H., and Cass R. Sunstein, 2008, Nudge: Improving Decisions About Health, Wealth, and Happiness, Yale University Press.

Tobin, James, 1958, Liquidity preference as behavior towards risk, Review of Economic Studies 25.

Varian, Hal, 1985, Divergence of opinion in complete markets: A note, Journal of Finance 40, 30917.

Varian, Hal, 1989, Differences of opinion in financial markets, in Courtenay C. Stone (ed.), Financial Risk: Theory, Evidence and Implications, Proceedings of the Eleventh Annual Economic Policy Conference of the Federal Reserve Bank of St. Louis, Kluwer, Boston, 3-37.

Wurgler, Jeffrey, and Katia Zhuravskaya, 2002, Does arbitrage flatten demand curves for stocks?, Journal of Business 75, 583-608. 
Figure 1. Observed Demand and Supply Schedules for Samsung Electronics on November 11, 2000

The opening auction orders graphs (black) reflect all buy and sell orders submitted for the opening auction that sets the open price. The 2:30 PM limit orders graphs (gray) reflect all outstanding limit orders as of 2:30 PM.

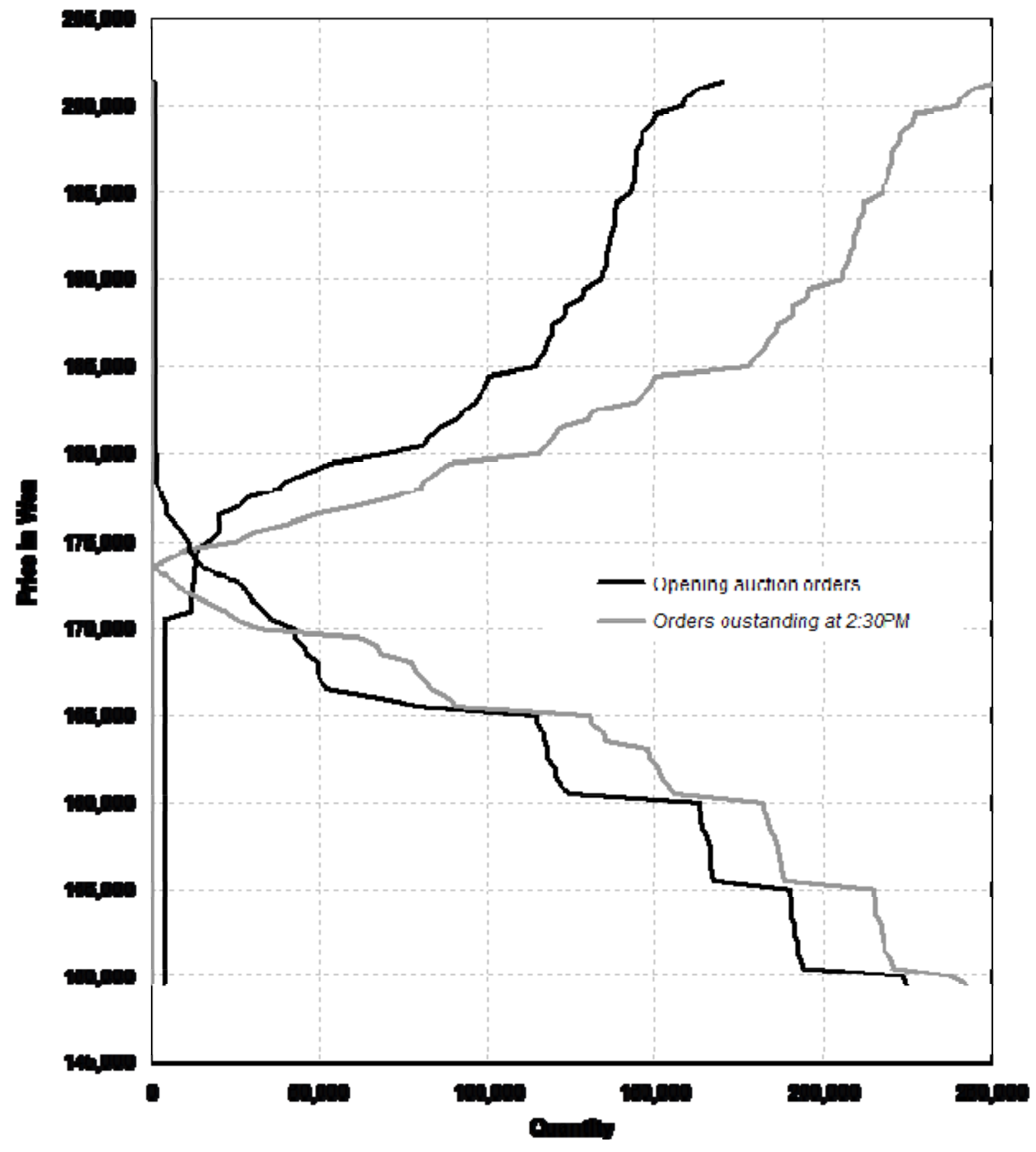


Figure 2. Demand and Supply Schedules in Real Time for Samsung Electronics on November 11, 2000

Demand and supply schedules for Samsung stock from the opening auction orders through the end of trading constructed from snapshots of complete limit order books taken every 15 minutes.

Panel A: Supply of Samsung at 15 minute intervals

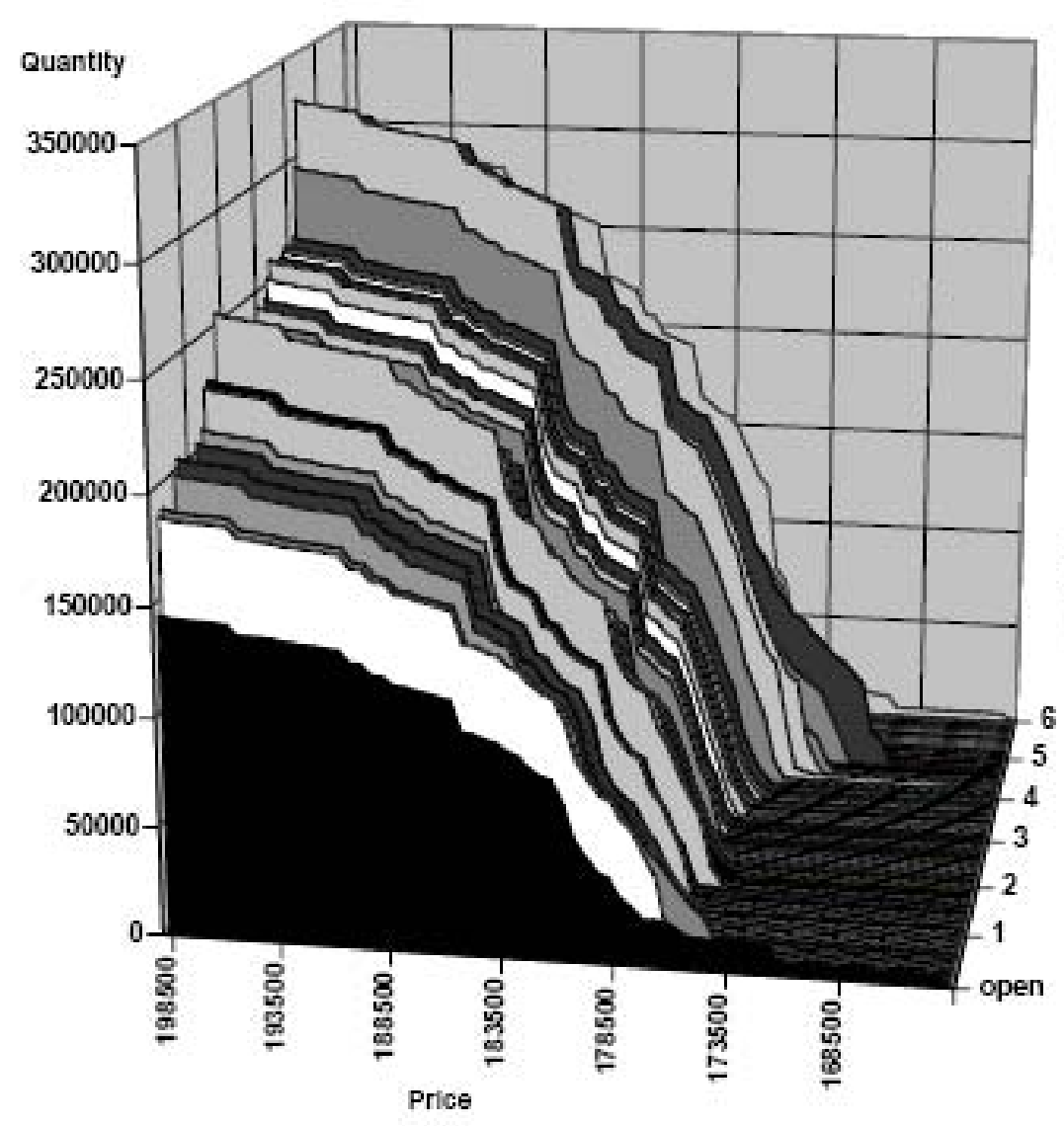

Panel B: Demand for Samsung at 15 minute intervals

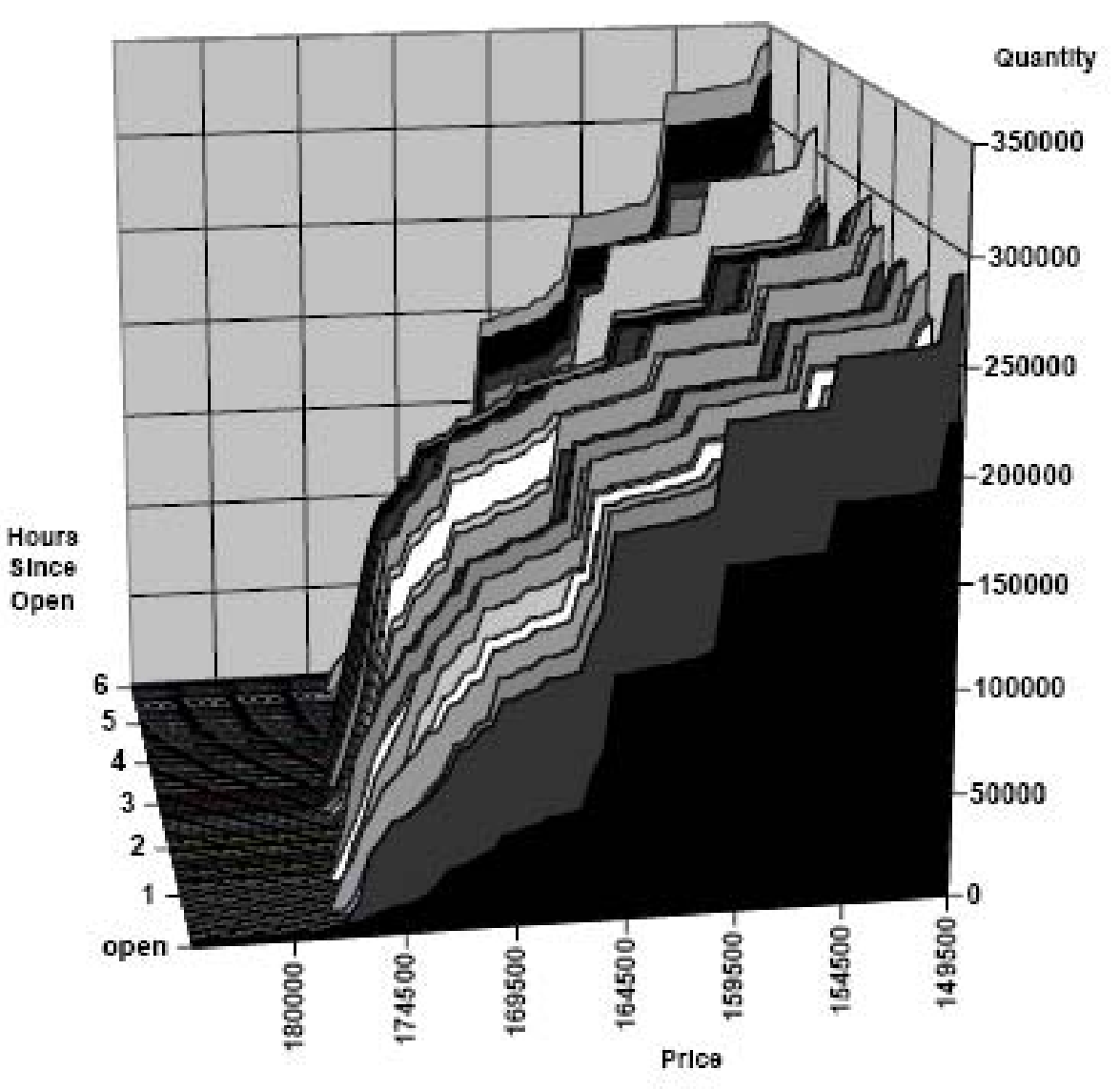


Figure 3. Mean Demand and Supply Elasticities of Individual Stocks over Time Each stock's elasticity of demand is the negative of the coefficient of log price in a regression explaining log quantity demanded at that price in the stock's limit order book; while its elasticity of supply is the coefficient in an analogous regression explaining log quantity supplied. Elasticities are estimated whenever the stock's relevant limit order schedule contains over five price-quantity pairs. Elasticities are measured twice each day from Dec. 1996 to Dec. 2000: first in the opening auction and again at 2:30 PM. Until December 5, 1998, the KSE was opened Saturday mornings, and the second elasticity is estimated at 11:30 AM on Saturdays. Daily elasticities are averaged across all stocks and this mean is graphed against time. The East Asian Financial Crisis period is the widened time axis segment from Nov. 1997 to Oct. 1998. The pre-crisis, and post- crisis periods are Dec. 1996 to Oct. 1997, and Nov. 1998 to Dec. 2000, respectively.

\section{Panel A: Opening Auction Elasticities}

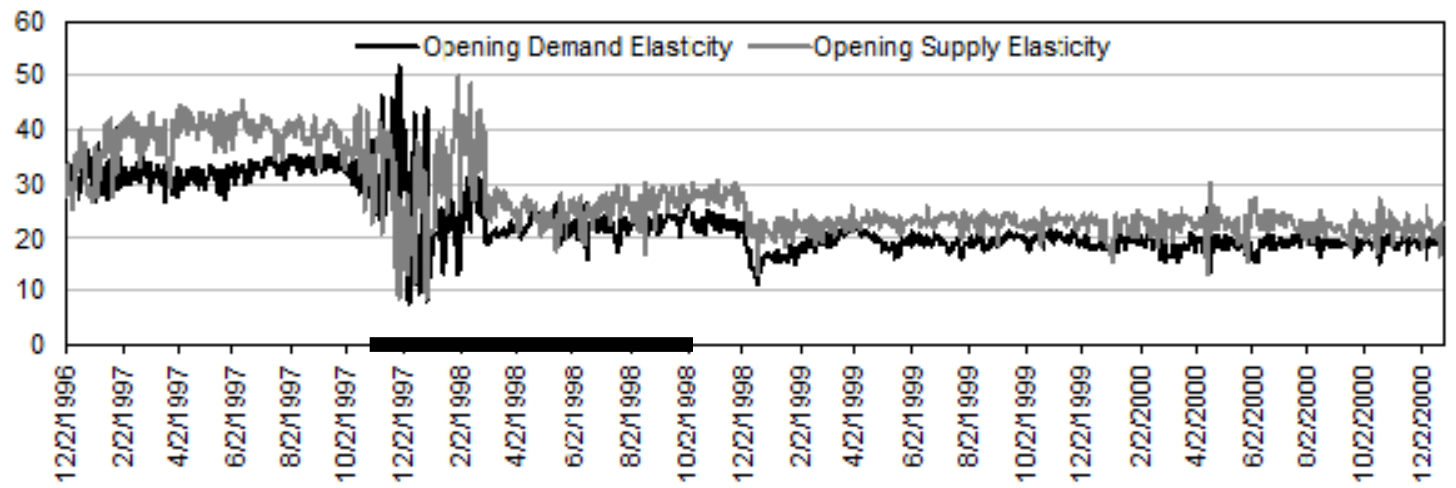

Panel B: 2:30 PM Elasticities

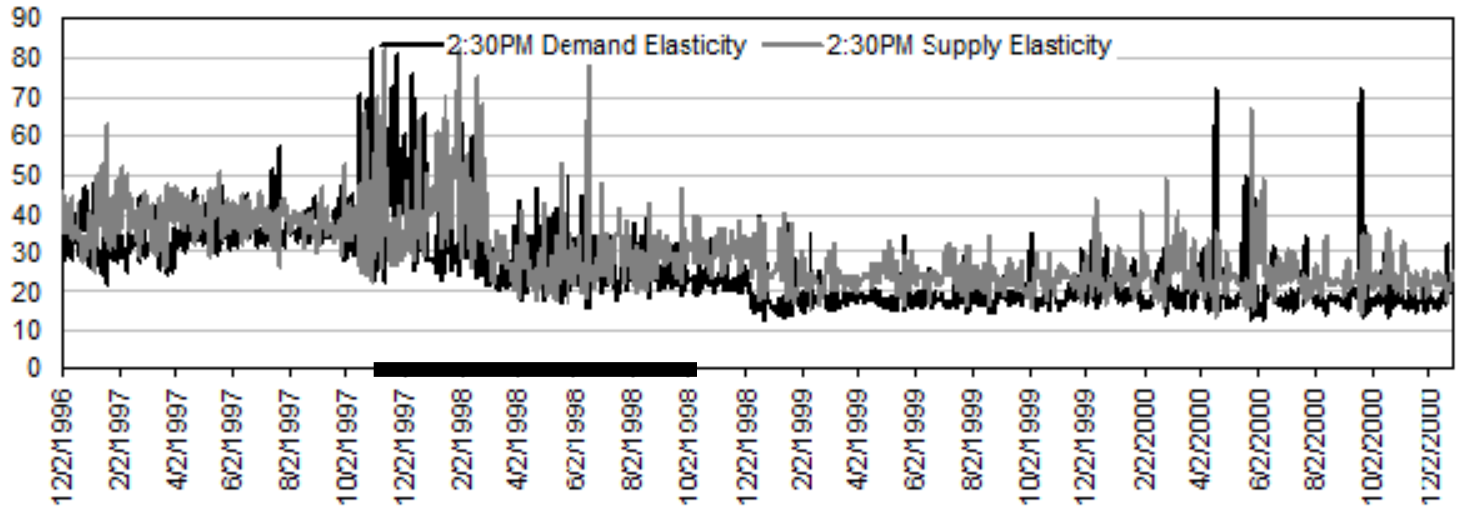

Panel C: KSE Index

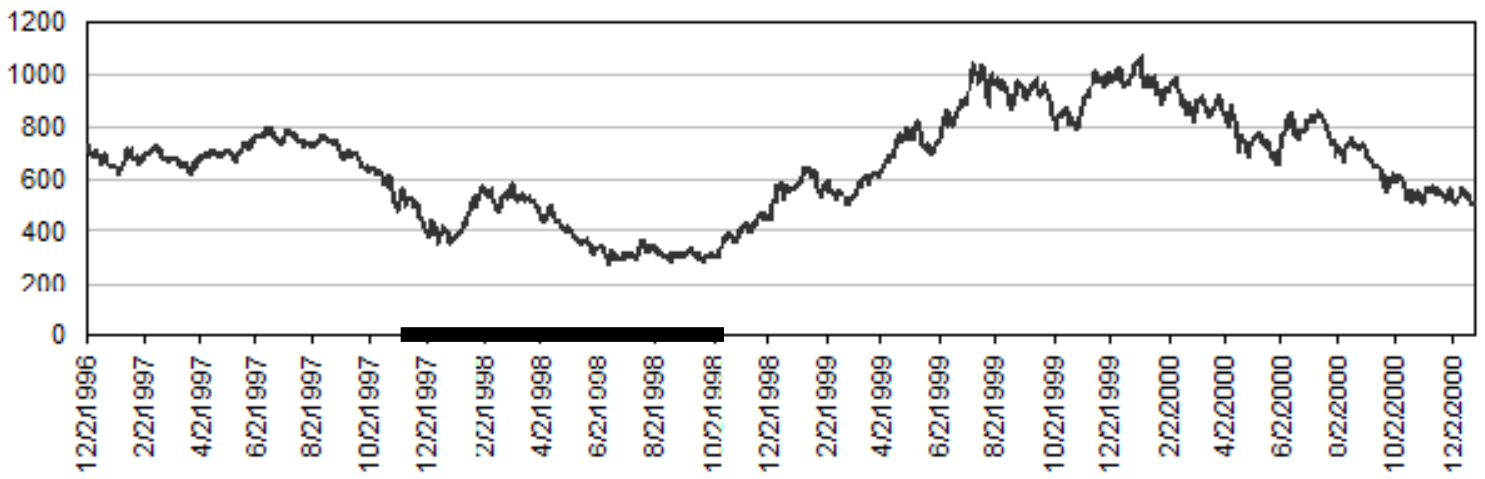


Figure 4. Mean Elasticities for the Whole Sample and Subsamples Dropping Limit Orders Priced within One, Two, or Three Percent of the Market Price.

Each stock's elasticity of demand is the negative of the coefficient of log price in a regression explaining log quantity demanded at that price in the stock's limit order book; while its elasticity of supply is the coefficient in an analogous regression explaining log quantity supplied. Elasticities are estimated whenever the stock's relevant limit order schedule contains over five price-quantity pairs, for the whole sample and subsamples where observations within $[-k \%, k \%]$ range around market prices are removed for $k=1,2$, or 3. Elasticities are measured twice each day from Dec. 1996 to Dec. 2000: first in the opening auction and again at 2:30 PM. Until December 5, 1998, the KSE was opened Saturday mornings, and the second elasticity is estimated at 11:30 AM on Saturdays. Daily elasticities are averaged across all stocks and then across days in specified periods: the entire sample, pre-crisis (December 1996 - October 1997), in-crisis (November 1997 - October 1998), and post-crisis (November 1998 - December 2000) periods.

Panel A: Demand Elasticities at Opening Auction and at 2:30 PM
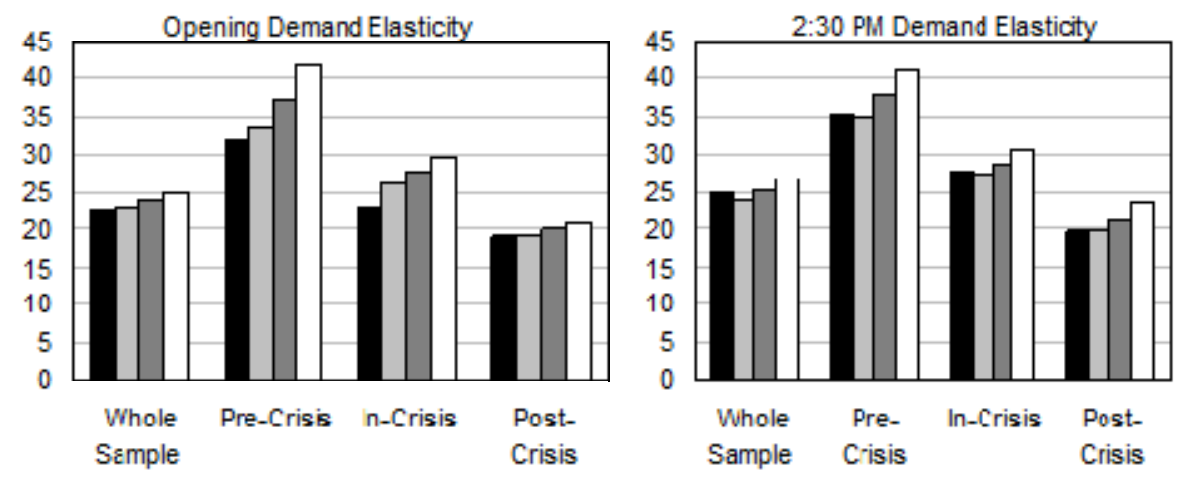

- Whole Data

$\square(-1 \%, 1 \%)$

Removed

$\square(-2 \%, 2 \%)$

Removed

$\square(-3 \%, 3 \%)$

Removed

Panel B: Supply Elasticities at Opening Auction and at 2:30 PM
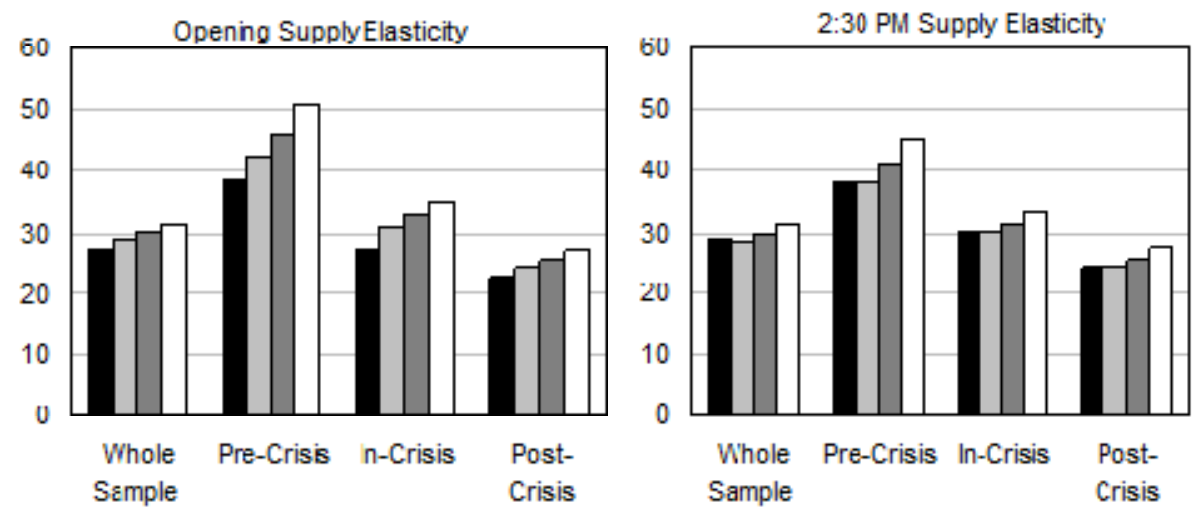

Whole Cata

$\square(-1 \%, 1 \%)$

Removed

$\square(-2 \%, 2 \%)$

Removed

$\square(-3 \%, 3 \%)$

Removed 
Figure 5. Relationship Between Daily Average Demand and Supply Elasticities Daily average supply elasticity is plotted against daily average demand elasticity, with observations color coded for pre-crisis (December 1996 - October 1997), in-crisis (November 1997 - October 1998), and post-crisis (November 1998 - December 2000) periods. Each stock's elasticity of demand is the negative of the coefficient of log price in a regression explaining log quantity demanded at that price in the stock's limit order book; while its elasticity of supply is the coefficient in an analogous regression explaining log quantity supplied. Elasticities are estimated whenever the stock's relevant limit order schedule contains over five price-quantity pairs; for the whole sample and subsamples dropping observations within one, two, or three percent of market prices. Elasticities are measured twice each day from Dec. 1996 to Dec. 2000: first in the opening auction and again at 2:30 PM. Until December 5, 1998, the KSE was opened Saturday mornings, and the second elasticity is estimated at 11:30 AM on Saturdays.

\section{Panel A: Elasticities at Opening Auction}
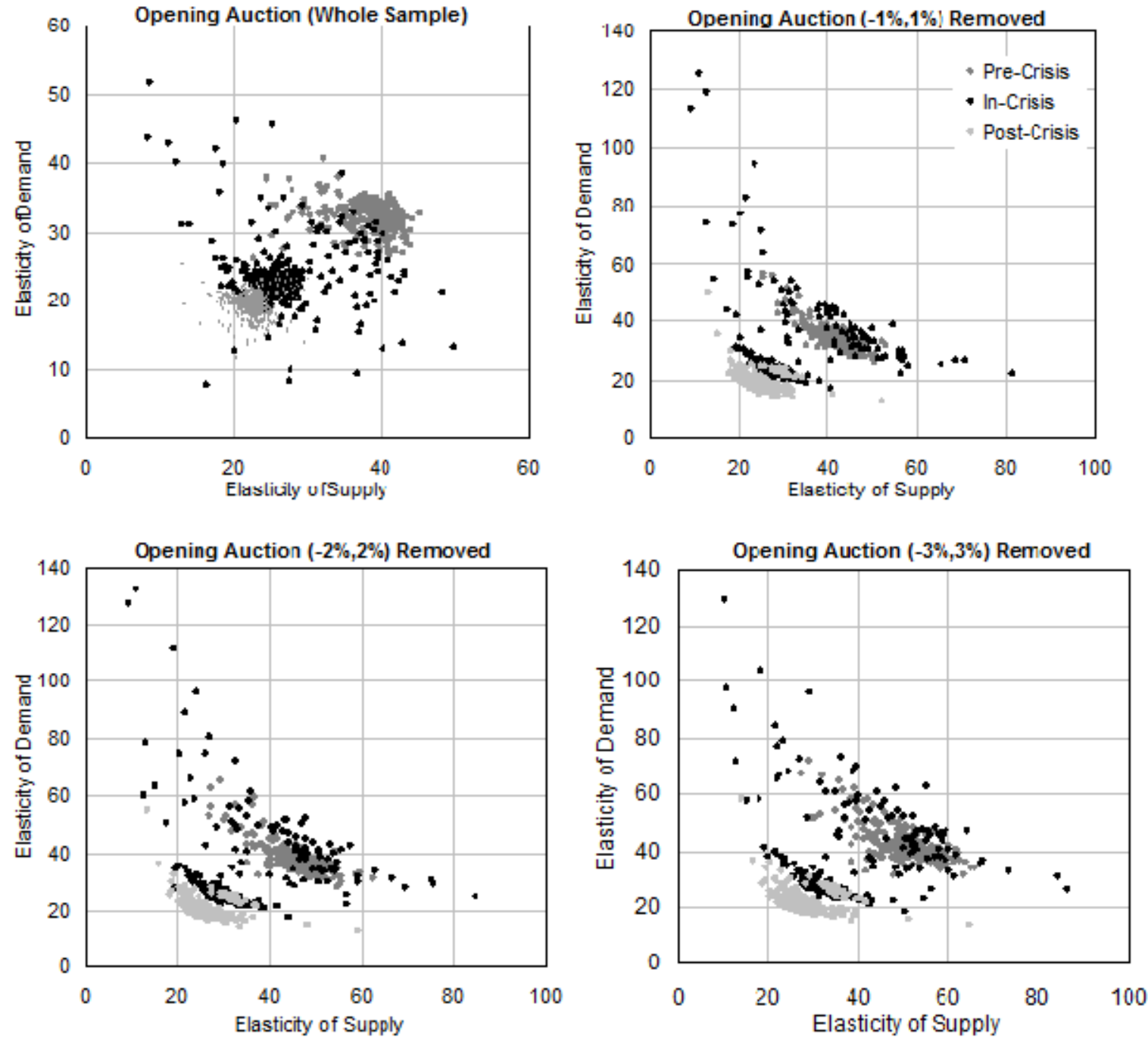
Panel B: Elasticities at 2:30 PM
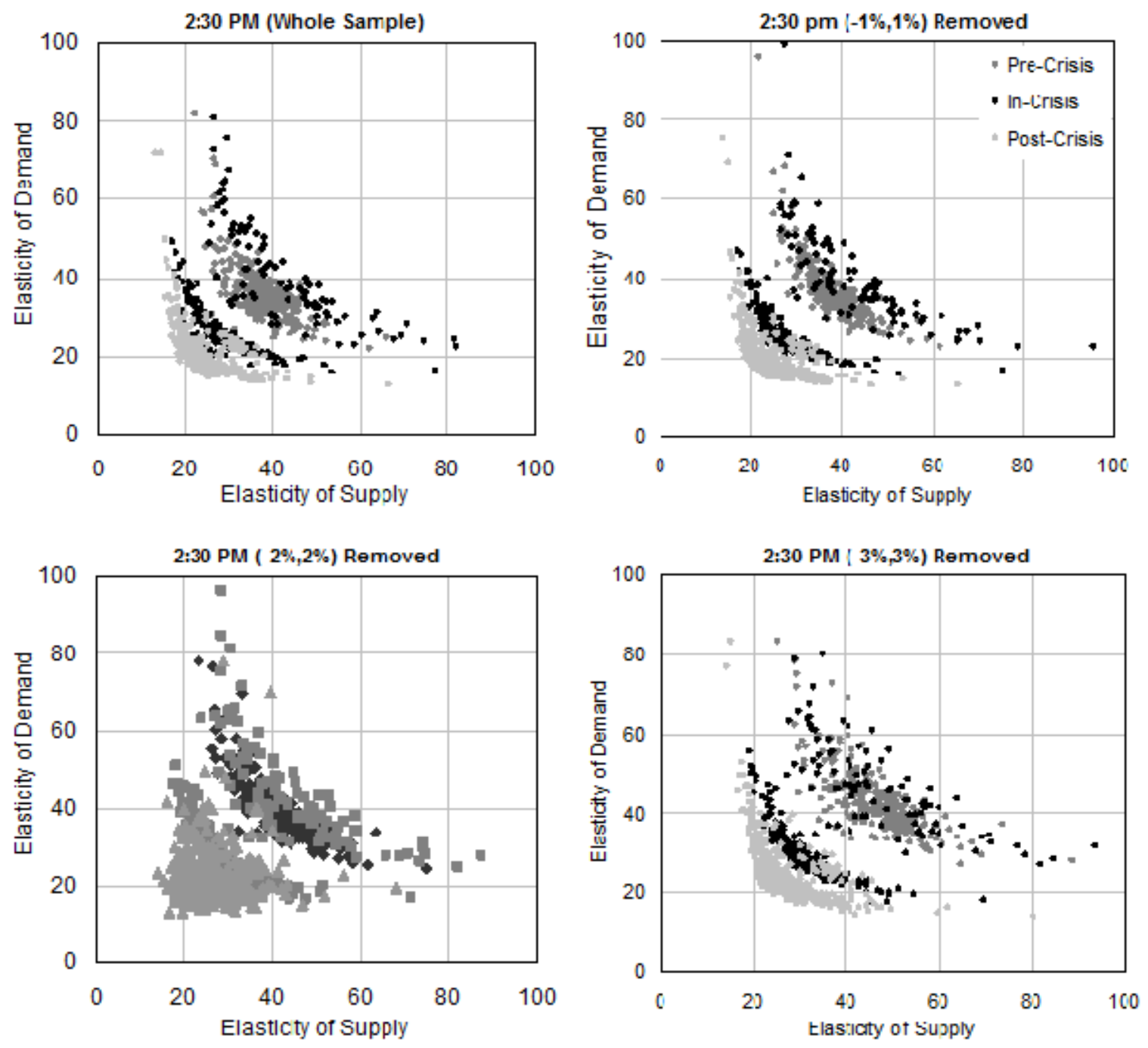
Figure 6. Correlations of Individual Stocks' Daily Mean Demand and Supply Elasticities, by Month

Each stock's elasticity of demand is the negative of the coefficient of log price in a regression explaining log quantity demanded at that price in the stock's limit order book; while its elasticity of supply is the coefficient in an analogous regression explaining log quantity supplied. Elasticities are measured from Dec. 1996 through Dec. 2000 at the open and at 2:30PM whenever the stock's relevant limit order schedule contains over five price-quantity pairs. Plots include correlations using the elasticities based on all limit orders, as well as those based on subsamples dropping limit orders within one, two, and three percent of the market prices. Until December 5, 1998, the KSE operated Saturday mornings, so the second elasticity on those days is estimated at 11:30AM. Correlations are of daily supply and demand elasticities, using all days in each month.

Panel A: Correlations of Daily Mean Demand and Supply Elasticities Measured at Opening Auctions

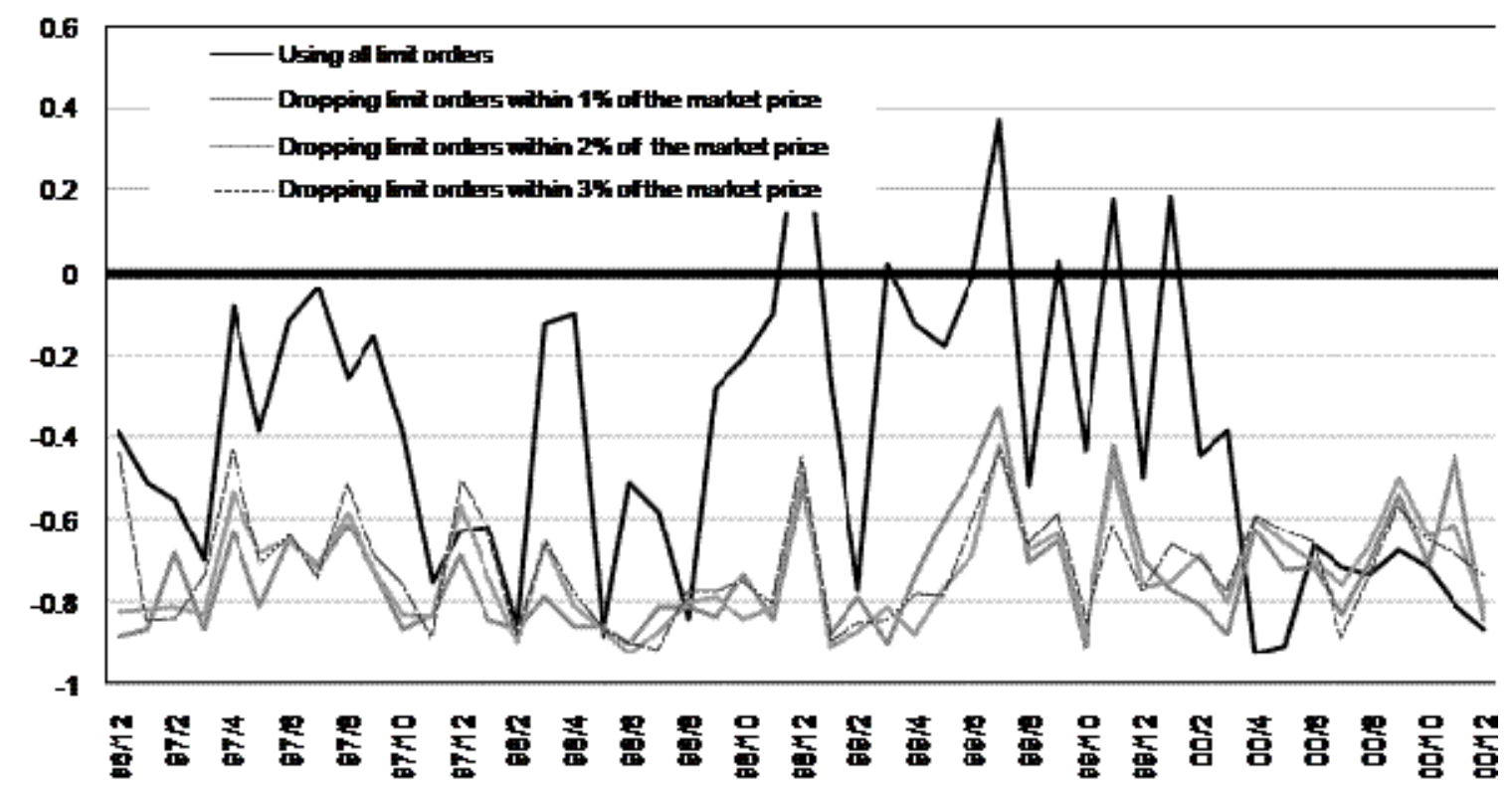

Panel B: Correlations of Daily Mean Demand and Supply Elasticities Measured at 2:30 PM

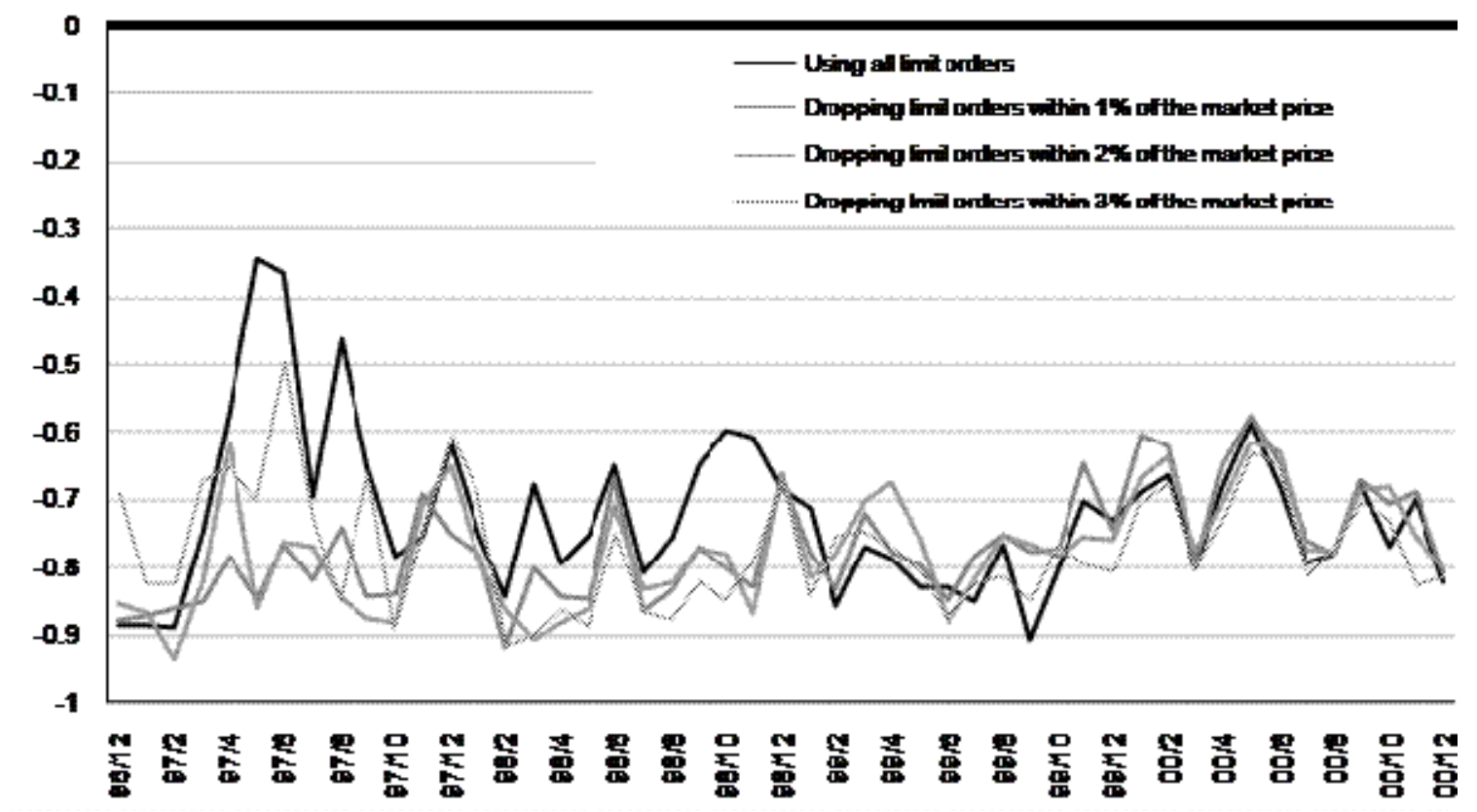


Table 1. Distribution of Orders and Trades

Orders can be limit or market orders, and can be submitted in an opening auction or in continuous trading throughout the day. Data are for common stocks trading on the Korea Stock Exchange (KSE) during December 1996 to December 2000. Each daily trading session is partitioned into an opening auction and the continuous trading during the rest of the day. Values in parentheses are average order sizes.

\begin{tabular}{|c|c|c|c|c|}
\hline \multicolumn{2}{|c|}{ Order Type } & Entire Day & Opening Auction & $\begin{array}{c}\text { Rest of Day } \\
\text { Continuous Market }\end{array}$ \\
\hline \multirow{3}{*}{ Buys } & Market & $\begin{array}{c}13,938,249 \\
(1,177.4)\end{array}$ & $\begin{array}{l}3,620,127 \\
(1,096.11)\end{array}$ & $\begin{array}{c}10,318,122 \\
(1,205.92)\end{array}$ \\
\hline & Limit & $\begin{array}{c}253,301,774 \\
(1,298.6)\end{array}$ & $\begin{array}{c}47,428,384 \\
(1,251.1)\end{array}$ & $\begin{array}{c}205,873,390 \\
(1,309.54)\end{array}$ \\
\hline & Total & $\begin{array}{c}267,240,023 \\
(1,292.28)\end{array}$ & $\begin{array}{l}51,048,511 \\
(1,240.11)\end{array}$ & $\begin{array}{c}216,191,512 \\
(1,304.6)\end{array}$ \\
\hline \multirow{3}{*}{ Sells } & Market & $\begin{array}{c}19,880,406 \\
(716.69)\end{array}$ & $\begin{array}{c}6,966,032 \\
(628.91)\end{array}$ & $\begin{array}{c}12,914,374 \\
(764.04)\end{array}$ \\
\hline & Limit & $\begin{array}{c}263,831,555 \\
(1,729.71)\end{array}$ & $\begin{array}{c}53,011,848 \\
(1,254.08)\end{array}$ & $\begin{array}{c}210,819,707 \\
(1,849.31)\end{array}$ \\
\hline & Total & $\begin{array}{c}283,711,961 \\
(1,658.72)\end{array}$ & $\begin{array}{c}59,977,880 \\
(1,181.47)\end{array}$ & $\begin{array}{c}223,734,081 \\
(1,786.66)\end{array}$ \\
\hline
\end{tabular}


Table 2. Limit Order Book Ranges

On each trading day, the limit order book prices for the opening auction are normalized by the opening price while the limit order book prices at 2:30 PM are normalized by the bid-ask mid-point. Then, quantities (in millions of shares) demanded and supplied in each price range are accumulated over the sample period of December 1996 to December 2000.

Panel A: Opening Auction

\begin{tabular}{ccccc}
\hline \multirow{2}{*}{\begin{tabular}{c} 
Limit $\begin{array}{c}\text { Order Price as Percent of } \\
\text { Opening Price }\end{array}$ \\
\cline { 2 - 5 }
\end{tabular}} & Quantity & $\begin{array}{c}\text { Percent of Total } \\
\text { Quantity }\end{array}$ & Quantity & $\begin{array}{c}\text { Percent of Total } \\
\text { Quantity }\end{array}$ \\
\hline Price $<85 \%$ & 4,987 & $14.00 \%$ & 64 & $0.20 \%$ \\
$85 \% \leq$ Price $<90 \%$ & 5,945 & 16.7 & 121 & 0.4 \\
$90 \% \leq$ Price $<95 \%$ & 8,206 & 23 & 315 & 1 \\
$95 \% \leq$ Price $<97 \%$ & 5,077 & 14.2 & 350 & 1.2 \\
$97 \% \leq$ Price $<98 \%$ & 2,790 & 7.8 & 314 & 1 \\
$98 \% \leq$ Price $<99 \%$ & 2,793 & 7.8 & 515 & 1.7 \\
$99 \% \leq$ Price $<100 \%$ & 2,712 & 7.6 & 757 & 2.5 \\
$100 \% \leq$ Price $<101 \%$ & 1,052 & 2.9 & 2,011 & 6.6 \\
$101 \% \leq$ Price $<102 \%$ & 631 & 1.8 & 2,069 & 6.8 \\
$102 \% \leq$ Price $<103 \%$ & 384 & 1.1 & 2,238 & 7.4 \\
$103 \% \leq$ Price $<105 \%$ & 415 & 1.2 & 4,715 & 15.5 \\
$105 \% \leq$ Price $<110 \%$ & 413 & 1.2 & 9,454 & 31.1 \\
$110 \% \leq$ Price $<115 \%$ & 160 & 0.4 & 5,564 & 18.3 \\
$115 \% \leq$ Price & 95 & 0.3 & 1,938 & 6.4 \\
\hline Total & 35,659 & $100.00 \%$ & 30,423 & $100.00 \%$ \\
\hline
\end{tabular}

Panel B: 2:30 PM

\begin{tabular}{ccccc}
\hline \multirow{2}{*}{$\begin{array}{c}\text { Limit Order Price as Percent of } \\
\text { the Bid-Ask Mid-Point }\end{array}$} & Quantity & $\begin{array}{c}\text { Percent of Total } \\
\text { Quantity }\end{array}$ & Quantity & $\begin{array}{c}\text { Percent of Total } \\
\text { Quantity }\end{array}$ \\
\cline { 2 - 5 } Price $<85 \%$ & 6,044 & $13.80 \%$ & & \\
$85 \% \leq$ Price $<90 \%$ & 7,984 & 18.2 & & \\
$90 \% \leq$ Price $<95 \%$ & 10,053 & 22.9 & & \\
$95 \% \leq$ Price $<97 \%$ & 6,359 & 14.5 & & \\
$97 \% \leq$ Price $<98 \%$ & 4,102 & 9.3 & & \\
$98 \% \leq$ Price $<99 \%$ & 4,907 & 11.2 & & \\
$99 \% \leq$ Price $<100 \%$ & 4,476 & 10.2 & 3,321 & $6.60 \%$ \\
$100 \% \leq$ Price $<101 \%$ & & & 4,521 & 9 \\
$101 \% \leq$ Price $<102 \%$ & & & 4,610 & 9.2 \\
$102 \% \leq$ Price $<103 \%$ & & & 8,651 & 17.2 \\
$103 \% \leq$ Price $<105 \%$ & & & 15,438 & 30.8 \\
$105 \% \leq$ Price $<110 \%$ & & & 8,563 & 17.1 \\
$110 \% \leq$ Price $<115 \%$ & & & 5,088 & 10.1 \\
$115 \% \leq$ Price & & & & \\
\hline Total & 43,925 & $100.00 \%$ & 50,193 & $100.00 \%$ \\
\hline
\end{tabular}


Table 3. Elasticities of KSE Stocks Before, During, and After the 1997 Crisis

Each stock's elasticity of demand is the negative of the coefficient of log price in a regression explaining log quantity demanded at that price in its limit order book; while its elasticity of supply is the coefficient in an analogous regression explaining log quantity supplied. Elasticities are measured twice each day from Dec. 1996 to Dec. 2000: first in the opening auction and again at 2:30 PM. Elasticities are estimated if over five price-quantity pairs exist for each firm, each day. All means and medians are significantly below infinity; that is, t-tests and rank tests, respectively, reject the null hypotheses of their reciprocals being zero at probability levels better than one percent. Until December 5, 1998, the KSE was opened Saturday mornings, and the second elasticity is estimated at 11:30 AM on Saturdays. Daily elasticities are averaged across all stocks and then observed across all days in the specified time periods: the entire sample, pre-crisis (December 1996 - October 1997), in-crisis (November 1997 - October 1998), and post-crisis (November 1998 - December 2000) periods.

\section{Panel A: Elasticity of Demand}

\begin{tabular}{|c|c|c|c|c|c|}
\hline Trading Session & Sub-Period & Observations & Mean & Median & Std. Dev. \\
\hline \multirow[t]{4}{*}{ Opening auction } & Entire sample period & 605,407 & 22.690 & 20.320 & 12.772 \\
\hline & Pre-crisis period & 120,588 & 32.078 & 30.015 & 16.765 \\
\hline & In-crisis period & 139,188 & 23.102 & 21.484 & 12.777 \\
\hline & Post-crisis period & 345,631 & 19.249 & 18.26 & 8.903 \\
\hline \multirow[t]{4}{*}{ 2:30 PM } & Entire sample period & 591,996 & 24.791 & 19.597 & 20.259 \\
\hline & Pre-crisis period & 122,214 & 35.189 & 29.652 & 24.322 \\
\hline & In-crisis period & 128,252 & 27.908 & 22.5 & 22.027 \\
\hline & Post-crisis period & 341,530 & 19.899 & 16.674 & 15.851 \\
\hline \multicolumn{6}{|c|}{ Panel B: Elasticity of Supply } \\
\hline Trading Session & Sub-Period & Observations & Mean & Median & Std. Dev. \\
\hline \multirow[t]{4}{*}{ Opening auction } & Entire sample period & 608,952 & 27.048 & 24.409 & 14.341 \\
\hline & Pre-crisis period & 125,565 & 38.594 & 36.88 & 18.215 \\
\hline & In-crisis period & 136,922 & 27.535 & 25.626 & 14.862 \\
\hline & Post-crisis period & 346,465 & 22.671 & 21.895 & 9.293 \\
\hline \multirow[t]{4}{*}{$2: 30 \mathrm{PM}$} & Entire sample period & 632,702 & 28.822 & 23.368 & 22.257 \\
\hline & Pre-crisis period & 147,261 & 38.096 & 32.885 & 24.297 \\
\hline & In-crisis period & 139,688 & 30.372 & 25.039 & 23.174 \\
\hline & Post-crisis period & 345,753 & 24.246 & 20.402 & 19.482 \\
\hline
\end{tabular}


Table 4. Panel Regressions of Supply on Demand Elasticities

Firm-level daily panel regressions are of $\tilde{\eta}_{j, t}^{S}=\alpha_{j}+\beta \tilde{\eta}_{j, t}^{D}+\varepsilon_{j, t}$, with $\tilde{\eta}_{j, t}^{S}$ and $\tilde{\eta}_{j, t}^{D}$ stock j's marketadjusted limit order supply and demand elasticities on day $t$ and $\alpha_{j}$ firm fixed effects. We obtain market-adjusted elasticities of firm $j$ by subtracting the day $t$ 's cross-sectional mean supply or demand elasticity across all firms from firm j's supply or demand elasticities. Each stock's elasticity of demand is the negative of the coefficient of log price in a regression explaining log quantity demanded; while its elasticity of supply is the coefficient in an analogous regression explaining log quantity supplied. Elasticities are estimated whenever a schedule has more than 5 price-quantity pairs. Whole elasticities are estimated using whole demand or supply limit order schedules, cored elasticities use all parts of the schedules except intervals within one, two, or three percent around market prices. Panel A uses elasticities at the opening auction and Panel B uses elasticity snapshots or limit order books at 2:30 PM, 30 minutes before the close. Until December 5, 1998, the KSE was opened Saturdays until noon, so the second elasticity is measured at 11:30 those days. The sample is partitioned into pre-crisis (Dec. 1996 - Oct. 1997), in-crisis (Nov. 1997 - Oct. 1998), and post-crisis (Nov. 1998 - Dec. 2000) periods. Probability levels ( $p$-values) are based on $t$-statistics adjusted for firm clustering.

Panel A: Panel Regression of Supply on Demand Elasticity at Opening Auction, with Day and Firm Fixed Effects and Firm-Clustered Standard Errors

\begin{tabular}{cccccc}
\hline $\begin{array}{c}\text { Price Quantity } \\
\text { Pairs }\end{array}$ & Entire Sample & $\begin{array}{c}\text { Pre-Crisis } \\
\text { Period }\end{array}$ & $\begin{array}{c}\text { In-Crisis } \\
\text { Period }\end{array}$ & $\begin{array}{c}\text { Post-Crisis } \\
\text { Period }\end{array}$ \\
\hline Whole & Estimate of $\beta$ & 0.006 & -0.006 & -0.016 & 0.007 \\
& $p$-value & 0.016 & 0.166 & 0.000 & 0.008 \\
& Adjusted $R^{2}$ & 0.027 & 0.046 & 0.044 & 0.049 \\
& Observations & 530,405 & 89,321 & 110,910 & 330,174 \\
Cored at 1\% & Estimate of $\beta$ & -0.107 & -0.129 & -0.146 & -0.083 \\
& p-value & 0.000 & 0.000 & 0.000 & 0.000 \\
& Adjusted $R^{2}$ & 0.019 & 0.042 & 0.027 & 0.020 \\
& Observations & 423,593 & 45,162 & 78,700 & 299,731 \\
Cored at 2\% $\%$ & Estimate of $\beta$ & -0.113 & -0.166 & -0.150 & -0.098 \\
& $p$-value & 0.000 & 0.000 & 0.000 & 0.000 \\
& Adjusted $R^{2}$ & 0.022 & 0.050 & 0.030 & 0.021 \\
& Observations & 372,210 & 24,547 & 64,633 & 283,030 \\
Cored at 3\% & Estimate of $\beta$ & -0.106 & -0.182 & -0.131 & -0.119 \\
& $p$-value & 0.000 & 0.000 & 0.000 & 0.000 \\
& Adjusted $R^{2}$ & 0.021 & 0.039 & 0.022 & 0.022 \\
& Observations & 321,442 & 10,324 & 50,022 & 261,096 \\
\hline
\end{tabular}


Panel B: Panel Regression of Supply on Demand Elasticity at 2:30 PM, with Day and Firm Fixed Effects and Firm-Clustered Standard Errors

\begin{tabular}{cccccc}
\hline $\begin{array}{c}\text { Price Quantity } \\
\text { Pairs }\end{array}$ & & Entire Sample & $\begin{array}{c}\text { Pre-Crisis } \\
\text { Period }\end{array}$ & $\begin{array}{c}\text { In-Crisis } \\
\text { Period }\end{array}$ & $\begin{array}{c}\text { Post-Crisis } \\
\text { Period }\end{array}$ \\
\hline Whole & Estimate of $\beta$ & -0.178 & -0.187 & -0.206 & -0.167 \\
& p-value & 0.000 & 0.000 & 0.000 & 0.000 \\
& Adjusted $R^{2}$ & 0.030 & 0.045 & 0.044 & 0.029 \\
& Observations & 544,224 & 102,645 & 111,088 & 330,491 \\
Cored at 1\% & Estimate of $\beta$ & -0.156 & -0.176 & -0.194 & -0.143 \\
& p-value & 0.000 & 0.000 & 0.000 & 0.000 \\
& Adjusted $R^{2}$ & 0.024 & 0.045 & 0.037 & 0.023 \\
& Observations & 491,918 & 70,914 & 99,680 & 321,324 \\
Cored at 2\% & Estimate of $\beta$ & -0.161 & -0.217 & -0.187 & -0.157 \\
& p-value & 0.000 & 0.000 & 0.000 & 0.000 \\
& Adjusted $R^{2}$ & 0.024 & 0.049 & 0.035 & 0.023 \\
& Observations & 420,849 & 36,908 & 80,716 & 303,225 \\
Cored at 3\% & Estimate of $\beta$ & -0.164 & -0.252 & -0.176 & -0.181 \\
& p-value & 0.000 & 0.000 & 0.000 & 0.000 \\
& Adjusted $R^{2}$ & 0.026 & 0.053 & 0.033 & 0.027 \\
& Observations & 351,460 & 14,539 & 59,708 & 277,213 \\
\hline
\end{tabular}

